\title{
What zinc supplementation does and does not achieve in diarrhea prevention: a systematic review and meta-analysis
}

\author{
Archana B Patel ${ }^{1,2+}$, Manju Mamtani ${ }^{1,3+}$, Neetu Badhoniya ${ }^{1}$ and Hemant Kulkarni ${ }^{1,3^{*}}$
}

\begin{abstract}
Background: Prevention of diarrhea has presented indomitable challenges. A preventive strategy that has received significant interest is zinc supplementation. Existing literature including quantitative meta-analyses and systematic reviews tend to show that zinc supplementation is beneficial however evidence to the contrary is augmenting. We therefore conducted an updated and comprehensive meta-analytical synthesis of the existing literature on the effect of zinc supplementation in prevention of diarrhea.

Methods: EMBASE ${ }^{\circledR}, M_{E D L I N E}{ }^{\circledR}$ and $\mathrm{CINAHL}^{\circledR}$ databases were searched for published reviews and meta-analyses on the use of zinc supplementation for the prevention childhood diarrhea. Additional RCTs published following the meta-analyses were also sought. Effect of zinc supplementation on the following five outcomes was studied: incidence of diarrhea, prevalence of diarrhea, incidence of persistent diarrhea, incidence of dysentery and incidence of mortality. The published RCTs were combined using random-effects meta-analyses, subgroup meta-analyses, meta-regression, cumulative meta-analyses and restricted meta-analyses to quantify and characterize the role of zinc supplementation with the afore stated outcomes.

Results: We found that zinc supplementation has a modest beneficial association (9\% reduction) with incidence of diarrhea, a stronger beneficial association (19\% reduction) with prevalence of diarrhea and occurrence of multiple diarrheal episodes (28\% reduction) but there was significant unexplained heterogeneity across the studies for these associations. Age, continent of study origin, zinc salt and risk of bias contributed significantly to between studies heterogeneity. Zinc supplementation did not show statistically significant benefit in reducing the incidence of persistent diarrhea, dysentery or mortality. In most instances, the 95\% prediction intervals for summary relative risk estimates straddled unity.

Conclusions: Demonstrable benefit of preventive zinc supplementation was observed against two of the five diarrhea-related outcomes but the prediction intervals straddled unity. Thus the evidence for a preventive benefit of zinc against diarrhea is inconclusive. Continued efforts are needed to better understand the sources of heterogeneity. The outcomes of zinc supplementation may be improved by identifying subgroups that need zinc supplementation.
\end{abstract}

\section{Background}

Preventing childhood diarrheas is difficult but important, especially in developing countries. An intensely studied and evaluated effort in this direction focuses on zinc supplementation since this micronutrient is believed to play a critical role in the pathogenesis of

\footnotetext{
*Correspondence: hemant_kulkarnius@yahoo.com

† Contributed equally

'Lata Medical Research Foundation, Nagpur, India

Full list of author information is available at the end of the article
}

childhood diarrheas. Zinc is one of several important trace elements that have far-reaching effects on multiple organs and systems and serves over 300 biological functions [1]. Therefore it is argued that chronic zinc deficiency may increase diarrhea susceptibility.

On the basis of the substantial body of biological evidence, it can be envisaged that zinc supplementation to children with zinc deficiency may help arrest or at least lessen diarrheal incidence and prevalence. For example, owing to the differential distribution of the prevalence

\section{Biomed Central}

(c) 2011 Patel et al; licensee BioMed Central Ltd. This is an Open Access article distributed under the terms of the Creative Commons Attribution License (http://creativecommons.org/licenses/by/2.0), which permits unrestricted use, distribution, and reproduction in any medium, provided the original work is properly cited. 
of zinc deficiency, the World Health Organization and WHO/UNICEF recommends therapeutic zinc supplementation for diarrhea only in developing countries but not in developed countries [2,3]. While guidelines for zinc supplementation during an episode of diarrhea are clearer, there is currently no unified view about the need to provide zinc supplementation as a preventive measure to curb the incidence and prevalence of diarrhea. Three published meta-analyses have thus far evaluated the use of zinc supplementation in the scenario of diarrhea prevention[4-6]. The first meta-analysis by Bhutta et al[5] included seven studies and showed an overall $18 \%$ reduction in incidence of diarrhea attributable to zinc supplementation. The second meta-analysis included 15 studies[4], reported a slightly lesser but still significant benefit of a $14 \%$ reduction in incidence of diarrhea. The most recent meta-analysis[6] included 24 studies with 33 distinct comparisons. It showed a $20 \%$ reduction in incidence of diarrhea. Interestingly, the meta-analyses by Aggarwal et al[4] reported a statistically significant heterogeneity across the published studies.

In spite of these elegant reports, there exist several gaps in the current understanding of the potential benefit of zinc supplementation as a prophylactic measure. First, the observed heterogeneity across published studies somewhat questions the reliability of the summary effect measures that have been heretofore ascribed to zinc supplementation. Second, several additional trials [7-12] have been published since the last meta-analysis and a formal synthesis inclusive of the newer evidence is currently lacking. Third, the published meta-analyses have reported the influence of zinc supplementation on overlapping as well as different diarrheal outcomes but a single compiled report on these different outcomes is not available. Finally, the temporal relevance of zinc supplementation as a public health measure against childhood diarrhea is not known. We therefore conducted the present study with the following three aims: i) to update the meta-analysis of preventive use of zinc in children for most commonly reported diarrheal outcomes; ii) to understand the sources of heterogeneity, if any; and iii) to understand if the evidenced-based benefit attributable to zinc has changed over time.

\section{Methods \\ Data Extraction}

We attempted to include all the recent published randomized controlled trials (RCT) that have been published after the three meta-analyses[4-6] were published. We also aimed to include additional past RCTs which may not been included in the previous meta-analyses. The search strategy and the search protocol are detailed in Figure 1A. To identify these studies we again searched the EMBASE $^{\circledR}$, CINAHL $^{\circledR}$ and MEDLINE ${ }^{\circledR}$ databases for recently published trials on zinc supplementation. We searched using the following keywords: "zinc" and "diarrhea" and "supplement" limited to "humans" and "trials". We included studies that gave zinc supplementation for at least two weeks, had a length of follow-up of at least four weeks and in which the relative risk estimates were either reported or computable. All trials that provided zinc supplements with or without other nutrients versus the same preparation minus zinc were included. Trials that began as therapeutic trials to treat acute or persistent diarrhea and followed the children for prevalence or incidence of subsequent diarrhea were also included, provided they fulfilled the inclusion criteria stated above. As shown in Figure 1A, we excluded trials that did not conform to a randomized controlled trial design; reported outcomes unrelated to diarrhea; had prohibitive number of co-interventions or co-infections or were not directly related with the topic of this review. Our exclusion criteria resulted in the exclusion of four trials that were included in previous meta-analysis for following reasons: human immune-deficiency coinfection [13], relative risk not computable [14], outcome unrelated to diarrhea [15] and several co-interventions [16].

Our search strategy identified a total of 37 trials [7-12,17-47], the details of which are listed in Table 1. After locating the studies, at least three investigators independently evaluated each trial and inputs from these sources were collated into the final data set. All the authors independently reviewed the studies; any discrepancies in the study evaluations were discussed and resolved during one-to-one meetings. The report of this review is provided in line with the PRISMA ${ }^{\circledR}$ guidelines (http://www.prisma-statement.org/index.htm) - the checklist and flowchart are provided separately (see Additional Files 1 and 2).

\section{Analytical approach}

We first attempted to classify the studies based on the outcomes they reported (Figure 1, right panel). We focused on five important and commonly reported outcomes: incidence of diarrhea, prevalence of diarrhea, incidence of persistent diarrhea, incidence of dysentery and incidence of mortality. For each outcome, we studied the reported effect sizes and the heterogeneity across studies. For these meta-analyses, we used the random effects model of DerSimonian and Laird [48].

For quantifying heterogeneity, we used two statistics: the $\mathrm{I}^{2}$ statistic and the $\tau^{2}$ statistic that represents the among-study variance. We also constructed 95\% confidence intervals for the $\tau^{2}$ statistic using non-parametric bootstrapping procedure [49] based on 5000 replicates. The two heterogeneity quantifying statistics have 


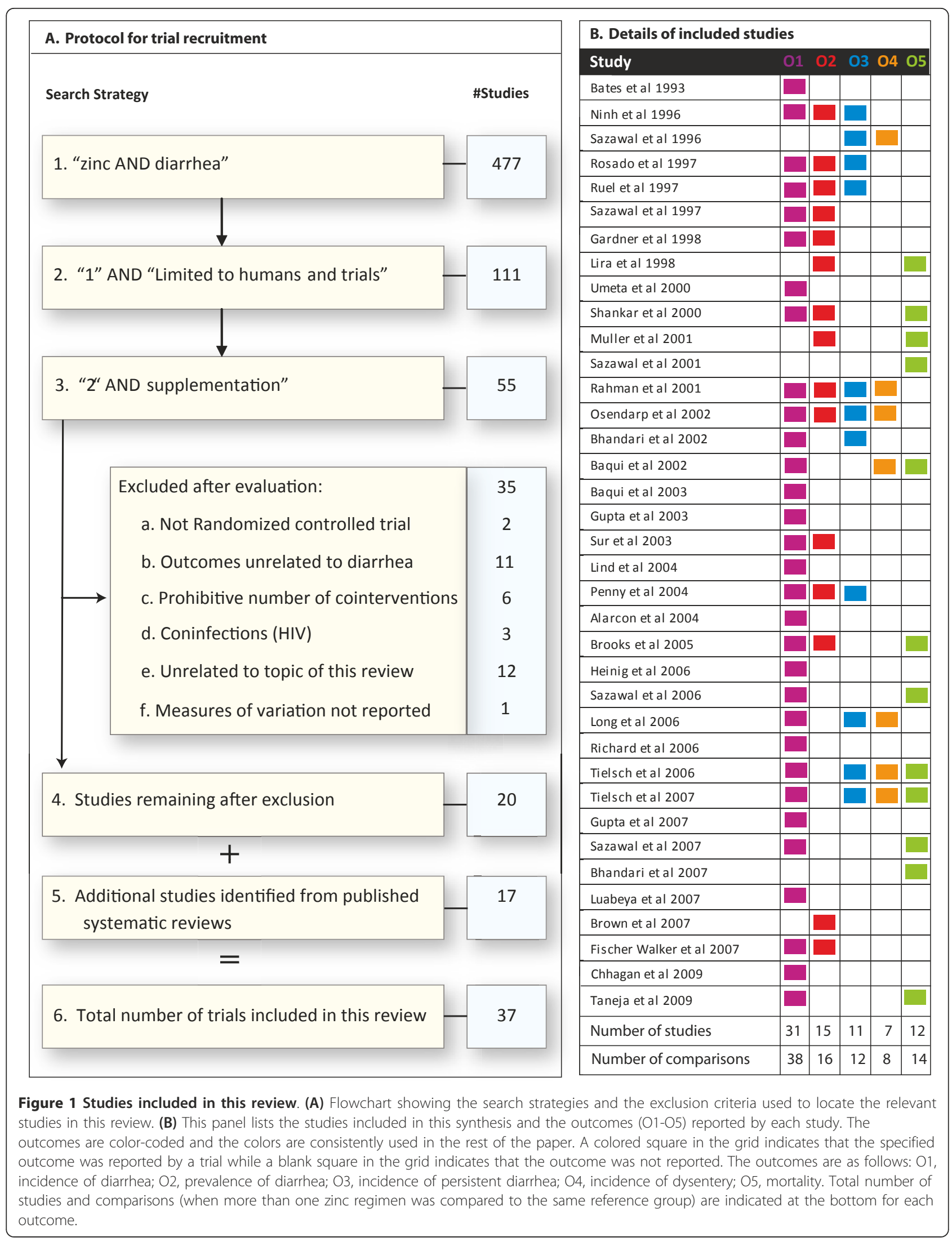


Table 1 Baseline characteristics of the studies included in the systemic review

\begin{tabular}{|c|c|c|c|c|c|c|c|c|c|c|c|}
\hline \multirow[t]{2}{*}{$\#$} & \multirow[t]{2}{*}{ Study } & \multirow[t]{2}{*}{ Country } & \multirow[t]{2}{*}{$\begin{array}{l}\text { Age } \\
(\mathrm{m})\end{array}$} & \multicolumn{2}{|c|}{$\begin{array}{c}\text { Sample } \\
\text { Size† }\end{array}$} & \multicolumn{4}{|c|}{ Zinc Supplementation } & \multicolumn{2}{|c|}{$\begin{array}{c}\text { Plasma } \\
\text { Zinc } \\
(\mu \mathrm{g} / \mathrm{dl})\end{array}$} \\
\hline & & & & $\mathrm{Zn}$ & $\begin{array}{l}\text { No } \\
\mathrm{Zn}\end{array}$ & $\begin{array}{l}\text { Dose } \\
(\mathrm{mg})\end{array}$ & $\begin{array}{l}\text { Frequency/ } \\
\text { wk }\end{array}$ & $\begin{array}{c}\text { Duration } \\
(\mathbf{w k})\end{array}$ & Salt & $\mathrm{Zn}$ & $\begin{array}{l}\text { No } \\
\mathrm{Zn}\end{array}$ \\
\hline 1 & Bates et al 1993 & The Gambia & $7-28$ & 55 & 54 & 70 & 2 & 60 & * & - & - \\
\hline 2 & Ninh et al 1996 & Vietnam & $4-36$ & 73 & 73 & 10 & 1 & 22 & Sulphate & - & - \\
\hline 3 & Sazawal et al 1996 & India & $6-35$ & 286 & 293 & 10 & 7 & 26 & Gluconate & 64.7 & 65.0 \\
\hline 4 & Rosado et al 1997 & Mexico & $18-36$ & 54 & 55 & 20 & 7 & 54 & Methionate & - & - \\
\hline 5 & Ruel et al 1997 & Guatemala & $6-9$ & 45 & 44 & 10 & 7 & 28 & Sulphate & 97.4 & 95.8 \\
\hline 6 & Sazawal et al 1997 & India & $6-35$ & 298 & 311 & 10 & 7 & 26 & Gluconate & - & - \\
\hline 7 & Gardner et al 1998 & Jamaica & $6-24$ & 31 & 30 & 5 & 7 & 12 & Sulphate & 64.6 & 65.0 \\
\hline 8 & Lira et al 1998 & Brazil & $0-6$ & 139 & 66 & 5 & 7 & 8 & Sulphate & - & - \\
\hline 9 & Umeta et al 2000 & Ethiopia & $6-12$ & 100 & 100 & 10 & 7 & 26 & Sulphate & 78.0 & 70.3 \\
\hline 10 & Shankar et al 2000 & Papua New Guinea & $6-60$ & 136 & 138 & 10 & 7 & 46 & Gluconate & 70.4 & 70.2 \\
\hline 11 & Muller et al 2001 & Burkina Faso & $6-31$ & 356 & 353 & 12.5 & 7 & 26 & Sulphate & - & - \\
\hline 12 & Sazawal et al 2001 & India & 0 & 581 & 573 & 5 & 7 & 35 & Sulphate & - & - \\
\hline 13 & Rahman et al 2001 & Bangladesh & $12-35$ & 325 & 161 & 20 & 7 & 2 & - & - & - \\
\hline 14 & Osendarp et al 2002 & Bangladesh & 1 & 152 & 149 & 5 & 7 & 24 & Acetate & 66.9 & 75.9 \\
\hline 15 & Bhandari et al 2002 & India & $6-30$ & 1241 & 1241 & 10 & 7 & 16 & Gluconate & - & - \\
\hline 16 & Baqui et al 2002 & Bangladesh & $3-59$ & 3974 & 4096 & 20 & 7 & 2 & Acetate & - & - \\
\hline 17 & Baqui et al 2003 & Bangladesh & 6 & 323 & 157 & 20 & 1 & 26 & Acetate & - & - \\
\hline 18 & Gupta et al 2003 & India & $6-41$ & 186 & 94 & 10 & 7 & 16 & Sulphate & - & - \\
\hline 19 & Sur et al 2003 & India & $0-12$ & 50 & 50 & 5 & 7 & 52 & Sulphate & - & - \\
\hline 20 & Lind et al 2004 & Indonesia & $6-12$ & 340 & 170 & 10 & 7 & 26 & Sulphate & - & - \\
\hline 21 & Penny et al 2004 & Peru & $6-36$ & 276 & 136 & 20 & 7 & 26 & Gluconate & - & - \\
\hline 22 & Alarcon et al 2004 & Peru & $6-35$ & 111 & 224 & 0.7 & 6 & 18 & Sulphate & - & - \\
\hline 23 & Brooks et al 2005 & Bangladesh & $2-12$ & 809 & 812 & 35 & 7 & 52 & Acetate & - & - \\
\hline 24 & Heinig et al 2006 & USA & $4-10$ & 41 & 44 & 5 & 7 & 28 & Sulphate & - & - \\
\hline 25 & Sazawal et al 2006 & Tanzania & $1-35$ & 8120 & 8006 & 10 & 7 & 56 & - & - & - \\
\hline 26 & Long et al 2006 & Mexico & $6-15$ & 389 & 198 & 20 & 7 & & Methionate & 71.0 & 76.0 \\
\hline 27 & Richard et al 2006 & Peru & $0.5-15$ & 428 & 215 & 20 & 7 & 28 & Sulphate & - & - \\
\hline 28 & Tielsch et al 2006 & Nepal & $1-36$ & 7297 & 14241 & 10 & 7 & 68 & Sulphate & - & - \\
\hline 29 & Tielsch et al 2007 & Nepal & $1-35$ & 20968 & 20308 & 10 & 7 & & Sulphate & - & - \\
\hline 30 & Gupta et al 2007 & India & $6-48$ & 854 & 858 & 25 & 2 & 26 & - & - & - \\
\hline 31 & Sazawal et al 2007 & Tanzania & $1-36$ & 21274 & 21272 & 10 & 7 & 68 & - & 78.0 & 79.0 \\
\hline 32 & Bhandari et al 2007 & India & $1-23$ & 47110 & 47249 & 10 & 7 & 52 & Sulphate & 64.0 & 64.2 \\
\hline 33 & Luabeya et al 2007 & South Africa & $4-6$ & 202 & 105 & 10 & 7 & 72 & Gluconate & 77.2 & 78.6 \\
\hline 34 & Brown et al 2007 & Peru & $6-8$ & 203 & 99 & 3 & 7 & 26 & Sulphate & 77.1 & 78.6 \\
\hline 35 & $\begin{array}{l}\text { Fischer Walker et al } \\
2007\end{array}$ & $\begin{array}{l}\text { India, Pakistan, } \\
\text { Ethiopia }\end{array}$ & $1-5$ & 554 & 556 & 10 & 7 & 2 & Sulphate & - & - \\
\hline 36 & Chhagan et al 2009 & South Africa & $6-24$ & 202 & 104 & 10 & 7 & 72 & Sulphate & - & - \\
\hline 37 & Taneja et al 2009 & India & 0 & 1026 & 1026 & 5 & 7 & 52 & Sulphate & 63.4 & 64.7 \\
\hline
\end{tabular}

$† Z n$, zinc supplemented group; No Zn, zinc withheld group, details of the actual comparisons are provided in Supplementary Table (see Additional File 4)

* Mentioned as acetate/gluconate; -, not mentioned 
distinct merits in quantifying heterogeneity. The $\mathrm{I}^{2}$ statistic can be compared across meta-analyses [50] and is related to the related $\tau^{2}$ statistic such that it represents the estimated proportion of the total or marginal variance of a single study that is due to the among-study variance[51]. Also, if a trial only reported the Cochrane $\mathrm{Q}$ test result for heterogeneity then the $\mathrm{I}^{2}$ statistic can be estimated from it using the formula $\mathrm{I}^{2}=(\mathrm{Q}-\mathrm{df}) / \mathrm{Q}$ with the minimum bound set to zero. On the other hand, there are two advantages of using the $\tau^{2}$ statistic: first it can be used to estimate the $95 \%$ prediction intervals for the global distribution of the estimated summary effect measure. Second, it can be used to estimate the proportion of populations that are likely to show a relative risk exceeding unity[52,53]. This parameter is referred to here as the opposite affects proportion [denoted in the rest of the paper by $\operatorname{Pr}(\mathrm{OE})$ ]. The theoretical details underlying these two uses of the $\tau^{2}$ statistic are described in details in a supplementary note (see Additional File 3).

Publication bias was examined using funnel plot [54] and the regression intercept method described by Egger at al[55]. We also used Duval and Tweedie's trim and fill approach to examine the publication bias[56]. To examine if the existing evidence points towards a changing benefit of zinc supplementation, we conducted cumulative meta-analyses in which each subsequently published study was added to meta-analysis and the procedure of DerSimonian and Laird [48] method repeated iteratively. We evaluated all the included studies to identify possible risks of bias using the risk of bias assessment tool recommended by $t$ the Cochrane Collaboration for Systematic Reviews [57]. The tool uses six questions (see legend to Figure six A) to which the answers can be summarized as no risk of bias, definite risk of bias or uncertain risk of bias. To quantify the overall risk of bias in a study we coded these three categories of responses as 1, 1.5 and 2, respectively and then summated the scores for all the six questions. Thus the total risk score varied in the range from 6 to 12 with a score of six indicating no risk of bias and a score of 12 indicating a highly biased study. We then assessed if this risk of bias score partly explained the variability in $R R$ estimates across studies.

We investigated the potential contributors to the heterogeneity with a three pronged approach: First, for continuous variables (age, plasma zinc concentration and dose of zinc) we conducted univariate meta-regression analyses as recommended by Higgins et al [50] and Thomson et al [58] and attempted to quantify the extent of contribution of the predictors to the heterogeneity. Second, we conducted sub-group meta-analyses analyses for the following categorical variables: continent of origin, zinc salt, countries classified by income categories, zinc only studies, studies not included in previous metaanalyses and studies with age-range up to 12 months. For classifying the trial country into income groups, we used the country-specific estimates of the Gross National Income provided by the World Bank using the Atlas method. (http://data.worldbank.org/data-catalog) Third, the age of study subjects posed a special challenge in our meta-analysis. Most of the studies reported the age as a range rather than mean. For the metaregression analyses explained in the first approach, we therefore used mid-point of the age range as an approximation for the average age in a study and used these mid-points for meta-regression. However, we also conducted a complementary analysis in which we conducted a set of restricted meta-analyses for each month of age. For example, if we wanted to estimate the benefit of zinc supplementation at 15 months of age then we included only those studies in which the age range straddled 15 months. We ran these restricted meta-analyses for each month of age over the range of 0-48 months and examined if the relative risk for the incidence of diarrhea was stable at all ages.

Another challenge to our analytical approach was the fact that some of the trials used a cluster-randomization procedure. It has been extensively described that the weights from a random effects model need to be appropriately adjusted to accommodate and overcome the potential influence of design effect on summary estimates in a meta-analysis $[59,60]$. We therefore, also adjusted the random-effects models for the design effect (which was reported in relevant trials) from cluster-randomized trials. The adjustment for design effect was done by multiplying the inverse-variance weight for a study by design effect. The design-effect for trials that did not use cluster randomization was treated as one. Statistical analyses were conducted using the Stata 10.2 (Stata Corp, College Station, TX) software package. For meta-analyses we used the metan.ado program written by Bradburn [61] whereas for the cumulative and restricted meta-analyses we used the metan.ado program iteratively through dedicated Stata scripts.

\section{Results}

We included 37 identified studies (220,805 subjects) for reports on one or more of the following five outcomes: incidence of diarrhea, prevalence of diarrhea, incidence of persistent diarrhea, incidence of dysentery and incidence of mortality(Figure 1B). The number of studies included for meta-analysis were: 31 for incidence of diarrhea [7-12,17-21,23,25-28,30,31,33-39,41,43-47], 15 for prevalence of diarrhea [12,23,24,29,31-36,38,39, $41,43,44], 11$ for incidence of persistent diarrhea [21,30,33-36,38-40,45,46], 7 for incidence of dysentery $[18,30,34,36,40,45,46]$ and 12 for incidence of mortality 
$[10,11,18,23,29,32,42,43,45,46]$. These studies represented $38,16,12,8$ and 14 distinct comparisons, respectively (Figure 1B). The details of the specified comparison groups for individual trials and the sources of these studies are given in the Supplementary Table 1 (see Additional file 4).

\section{Association of zinc supplementation with diarrheal incidence}

The summary relative risk estimate for incidence of diarrhea was contributed by a total of 69934 and 75028 children in zinc and comparison groups, respectively. Since some studies used more than one groups compared to the same reference group, the total numbers of comparisons used in this meta-analysis were 38 as shown in Figure 2A. Our results indicated that there was a $9 \%$ [summary relative risk estimate size $0.91,95 \%$ CI 0.87-0.95] lower incidence of diarrhea among children who received zinc supplementation (Figure 2A). The strength of this association did not change even after adjusting for the design effect from cluster-randomized trials (Figure 2A) and thus for the reason of simplicity we report the findings from a standard random effects model. The estimated value of $\tau^{2}$ was 0.0107 (95\% confidence interval $0.0049-0.0217)$. Using this value of the among-study variance indicated that the 95\% prediction interval for the summary relative risk estimate was $0.73-1.13$ and the $\operatorname{Pr}(\mathrm{OE})$ was $18 \%$ indicating that at the level of populations it may be premature to assume a clear benefit of zinc supplementation and that approximately $18 \%$ populations are likely to show a relative risk estimate exceeding unity.

We considered two potential sources for a potentially biased summary RR estimate in our meta-analysis. First, since zinc was supplemented during episodes of acute diarrhea in two trials $[12,18]$ we considered whether inclusion of these trials could have influenced our metaanalysis. Sensitivity analyses (see Additional file 5) showed that exclusion of these two trials had negligible impact on the results of meta-analysis. Second, the funnel plot (Figure 2B) indicated that was no significant publication bias (Egger's test: bias $=-0.8 ; \mathrm{p}=0.12$; Figure $1 \mathrm{~B})$. We evaluated the publication bias using Duval and Tweedie's trim and fill approach also and found that no trimming was required and the results therefore corroborated those of the Egger's test.

To determine if there has been a temporal change in the observed benefit of zinc supplementation we conducted two sets of analyses. We first conducted cumulative meta-analyses for the summary relative risk estimate for incidence of diarrhea by iteratively including all studies that predated a specific trial. Significant benefit of zinc was observed onwards from the fifth study group. (Figure 2C) A striking observation from this cumulative meta-analysis was that there was trend for a monotonically decreasing benefit of zinc with the chronological rank of the studies. We thus considered the possibility of using calendar year of publication year as a predictor of the relative risk using meta-regression but could not conduct those analyses as the distribution of this variable was skewed towards more recent years (Shapiro-Wilk's p $=0.027$ ). Alternatively, to keep the size of subgroups balanced, we categorized the trials into four classes based on the quartiles of the publication year. We observed (Figure 2D) that a significant protective benefit of zinc was observed in the first two quartiles of publication year but not in the third and fourth ones further substantiating the likelihood that the accumulation of more recent evidence points towards a diminished preventive benefit ascribable to zinc supplementation. To affirm this point further, we considered whether the trials included in our review that were not available for previous meta-analyses demonstrated a lack of beneficial association of zinc supplementation with diarrheal incidence. We observed that seven comparison groups from five new trials $[7,8,11,12,62]$ indeed provided no evidence in favor of zinc supplementation [summary RR estimate 0.99, 95\% CI 0.93 - 1.05] while the meta-analysis of the remaining 31 comparisons yielded statistically significant beneficial association with zinc supplementation [summary RR 0.90, 95\% CI 0.85 - 0.95].

An alternative way to measure the potential influence of zinc on diarrheal incidence is to consider the outcome of multiple episodes as has been done for other conditions[51,63]. We thus examined if zinc supplementation affords a protection against occurrence of multiple episodes of diarrhea. Only four trials [12,26,33,64] explicitly stated this outcome. The remaining trials did not clearly state whether the incidence is reported for only first episodes or for subsequent episodes as well. Three trials $[12,26,33]$ reported the outcome as occurrence of $\geq 2$ episodes of diarrhea while the remaining trial [64] categorized the outcome as 0 episodes, 1-3 episodes, 4-6 episodes and >6 episodes. All the four trials suggested a strong protective association of zinc supplementation with multiple episodes of diarrhea. Meta-analytic summary of three trials $[12,26,33]$ indicated that zinc supplementation afforded a $31 \%$ protection against occurrence of $\geq 2$ episodes [summary relative risk estimate $=0.69,95 \%$ CI $0.53-0.95,95 \%$ prediction interval $0.44-1.09, \operatorname{Pr}(\mathrm{OE}) 1.9 \%$ ] although there was heterogeneity in the results $\left(\mathrm{I}^{2} 68 \%, \tau^{2} 0.0317,95 \% \mathrm{CI}\right.$ for $\tau^{2}$ $0.0231-0.284)$

\section{Investigation of heterogeneity across studies on diarrheal} incidence

In both the overall and the cumulative meta-analyses there was a statistically significant heterogeneity of 


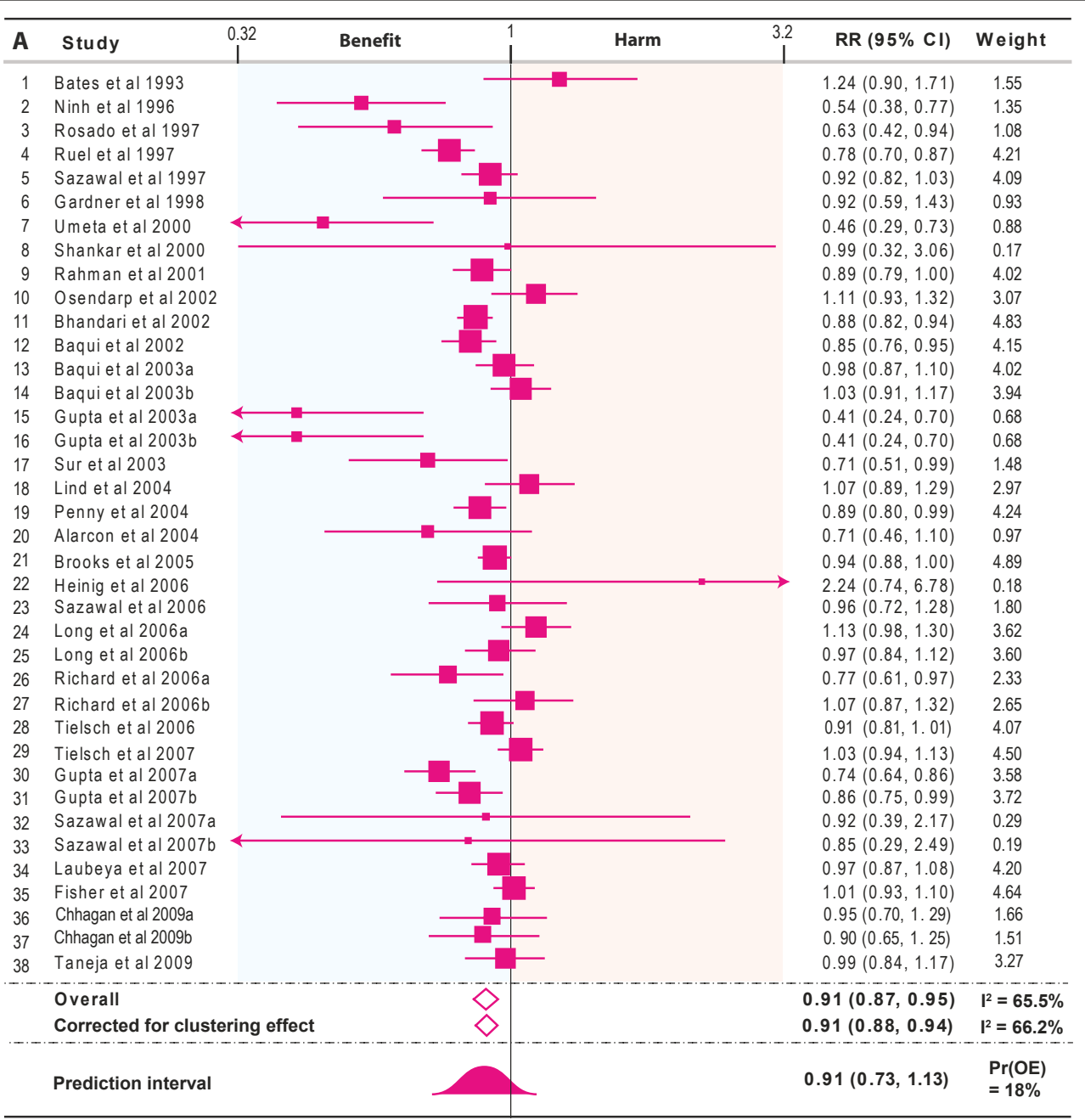

B

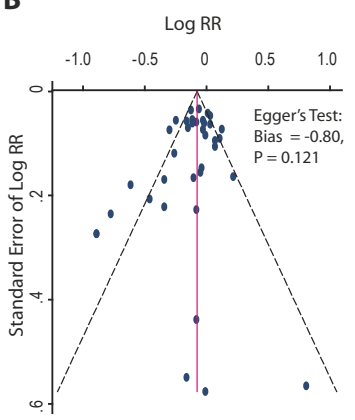

C

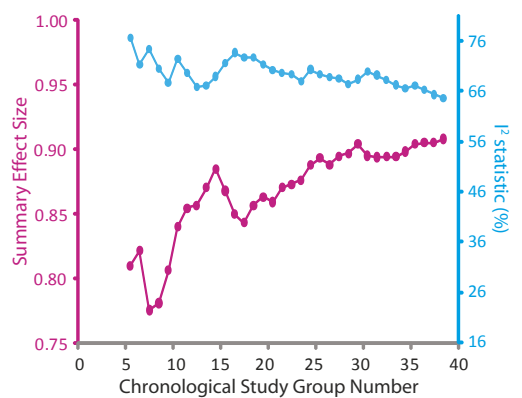

\section{D}

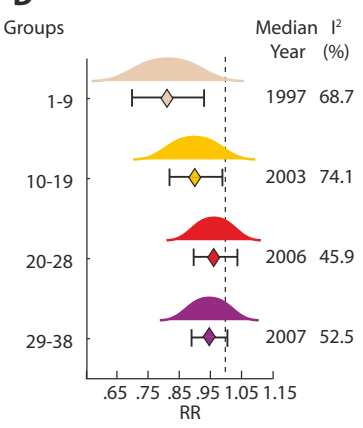

Figure 2 Meta-analysis of the influence of preventive zinc supplementation on the incidence of diarrhea. (A) Forest plot showing the point (squares proportional to study weight) and 95\% confidence interval (error bars) estimates for each study. Colored background indicates harm (pink) or benefit (blue) of zinc supplementation. Summary relative risk estimate is shown as a diamond both by the random effects model ("Overall") and corrected for the design effect from cluster-randomized trial ("Corrected for clustering effect"). The 95\% prediction interval (PI) is shown as a standard normal curve. Suffixes a and b indicate comparisons within a single study against the same placebo as detailed in Supplementary Table (see Additional File 4). RR, relative risk; weight, percentage weight; Pr(OE) opposite effects proportion. (B) Funnel plot for the investigation of publication bias. (C) Cumulative meta-analyses of chronologically ordered studies. Results are shown as the point estimate of the effect size (purple diamonds aligned to the left $y$-axis) and the $I^{2}$ statistic (blue squares aligned to the right $y$-axis). Results are shown from study group five onwards for which significant effects were observed (D) Contribution of calendar year to zinc supplementation. Results are represented as point estimates (diamonds) 95\% Cl (error bars) and 95\% PI (standardized normal curves). Heterogeneity is shown as $1^{2}$. The estimates for $\tau^{2}$ were: study groups 1-9: 0.0232 (95\% Cl 0.0029-0.1407); study groups 10-19: 0.0143 (95\% Cl 0.0033-0.0712); study groups 20-28: 0.0055 (95\% Cl 0.0000-0.0313); and study groups 29-38: 0.0062 (95\% Cl 0.0000-0.0231). 
effects across the published studies ( $\mathrm{I}^{2}$ 65.5\%, $\tau^{2}$ 0.0107, $95 \%$ CI for $\left.\tau^{2} 0.0049-0.0217\right)$. We therefore proceeded to investigate if the reported trial characteristics can partially explain this heterogeneity. Specifically, we examined the contribution of the following variables to heterogeneity: age, continent of origin, country economy (as a surrogate for prevalence of zinc deficiency), zinc salt, duration of zinc supplementation, dose of zinc supplementation and co-interventions. As shown in Table 1 , only 12 of the included studies reported the baseline plasma zinc level and hence we could not the influence of this variable on heterogeneity.

We examined the contribution of age to heterogeneity in three ways. First, the restricted meta-analysis for each month of age showed (Figure 3A) that the relative risk of diarrhea was strongly inversely correlated with age. We found that there was a strong positive correlation (Pearson's $r=0.82, \mathrm{p}<0.0001$ ) between age and the summary relative risk for incidence of diarrhea indicating that the beneficial association of zinc supplementation, on an average, increased by $0.31 \%$ for each month of age starting from a benefit of $7.4 \%$ (95\% CI 5.7\% 9.2\%) at age zero. Maximum benefit of zinc supplementation (26\%) was observed above 36 months but this association was contributed to by only 6 studies (Figure $3 \mathrm{~A})$. Second, using the alternative approach of metaregression we found that age explained $6.3 \%$ of the heterogeneity across studies and had a significant association $(\mathrm{p}=0.014)$ with the reported incidence of diarrhea (Figure 3B). Third, we categorized the included studies into two groups - those in which the age range was entirely below 1 year and the remaining studies. Subgroup meta-analysis using this dichotomization indicated (Table 2) that statistically significant association could not be found in studies recruiting all children less than one year of age. Thus, three complementary approaches implied that zinc supplementation may benefit more by restricting it to higher ages. It should be noted however, that the $95 \%$ prediction intervals were non-significant at all ages.

In the subgroup analyses, we found that the 19 study groups from Asia $[11,12,18,19,21,23,25,26,28,33,34$, 41,44-46] showed a significant reduction in diarrheal incidence but with large heterogeneity among study groups. In contrast, studies from Americas [17,27, 30,31,35,37-39], Africa [7-10,20,47] or Oceania [43] could not demonstrate a significant benefit of zinc for this outcome (Table 2). Corroborating these results, we also found (Table 2) that trials from the countries in the lower middle income group $[11,12,25,26,28,39,43,44$, $64,65]$ demonstrated the strongest benefit of zinc supplementation while trials from countries in the upper middle $[7,8,17,30,31,35,37,38]$ or high income group [27] did not demonstrate such a benefit. Surprisingly, we found that studies from the low income group countries $[9,10,18-20,23,33,34,36,45-47]$ also failed to demonstrate beneficial utility of zinc against diarrheal incidence. With regard to zinc salt, majority of the studies used either zinc sulphate (18 study groups, [9,11,12,17,25, $27,28,31,33,37,39,44-46])$ or zinc gluconate (7 study groups, $[7,8,21,35,43,65])$. We found that the trials using zinc gluconate showed the most significant reduction in diarrheal incidence with no heterogeneity while the trials using zinc sulphate (and those which did not mention the salt used) also showed a statistically significant reduction in diarrheal incidence. The trials that used
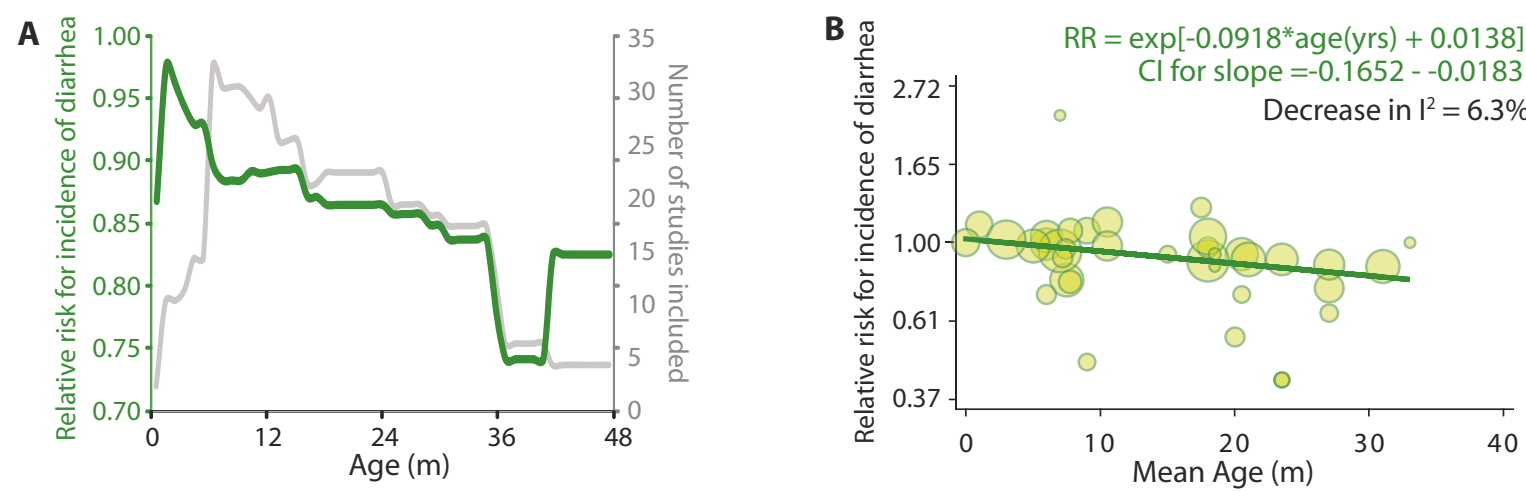

Figure 3 Association of age of the study subjects with the benefit of zinc supplementation. (A) Results from restricted meta-analysis for each month of age (x-axis). Restricted meta-analysis was conducted for each month of age by including only those studies in which the range of age of the study subjects straddled the selected month of age. Left $y$-axis (green) shows the relative risk for incidence of diarrhea while the right $y$-axis (grey) shows the number of studies included in meta-analysis (B) Meta-regression. In this analysis the mid-point of the age range for each study was meta-regressed onto the relative risk of observed diarrheal incidence in that study. Each circle represents a trial - the diameter of a circle is proportional to the standard error in that study. Dark green line is the predicted regression line. Meta-regression on this variable indicated that accounting for age would reduce the $\mathrm{I}^{2}$ statistic by $6.3 \%$. $\mathrm{P}_{\text {slope }}$ indicates the significance value for the test of a two-tailed null hypothesis that the slope of the regression line is zero. 
Table 2 Results of subgroup analysis for the outcome of diarrheal incidence

\begin{tabular}{|c|c|c|c|c|c|c|c|c|}
\hline Characteristic & $\mathrm{N}$ & SRR & $95 \% \mathrm{Cl}$ & $95 \% \mathrm{PI}$ & $I^{2}(\%)$ & $\tau^{2}$ & $95 \% \mathrm{Cl}$ for $\tau^{2}$ & $\operatorname{Pr}(\mathrm{OE}) \%$ \\
\hline \multicolumn{9}{|l|}{ Age category } \\
\hline Age range $<=12$ months & 12 & 0.95 & $0.88-1.02$ & $0.77-1.18$ & 69.9 & 0.0099 & $0.0000-0.0345$ & 30.3 \\
\hline Remaining studies & 26 & 0.89 & $0.83-0.94$ & $0.71-1.12$ & 61.9 & 0.0114 & $0.0029-0.0284$ & 13.8 \\
\hline \multicolumn{9}{|l|}{ Type of comparison* } \\
\hline Zinc versus placebo & 25 & 0.88 & $0.82-0.95$ & $0.67-1.16$ & 72.2 & 0.0173 & $0.0069-0.0404$ & 16.6 \\
\hline Zinc $+x$ versus $x$ & 5 & 0.90 & $0.85-0.96$ & $0.84-0.96$ & 6.7 & 0.0003 & $0.0000-0.0256$ & $<0.001$ \\
\hline Zinc $+x+y$ versus $y$ & 8 & 0.98 & $0.82-1.04$ & $0.80-1.20$ & 21.2 & 0.0014 & $0.0000-0.0269$ & 29.5 \\
\hline \multicolumn{9}{|l|}{ Continent of origin } \\
\hline Africa & 8 & 0.92 & $0.79-1.08$ & $0.67-1.26$ & 43.7 & 0.0185 & $0.0000-0.1702$ & 27.0 \\
\hline Asia & 19 & 0.91 & $0.86-0.96$ & $0.74-1.12$ & 72.2 & 0.0099 & $0.0038-0.0252$ & 17.2 \\
\hline Americas & 10 & 0.90 & $0.80-1.01$ & $0.66-1.22$ & 68.7 & 0.0192 & $0.0059-0.0756$ & 22.4 \\
\hline Oceania & 1 & 0.99 & $0.32-3.06$ & - & - & - & - & - \\
\hline \multicolumn{9}{|l|}{ Country economy } \\
\hline Low income & 14 & 0.94 & $0.87-1.01$ & $0.76-1.16$ & 63.4 & 0.0089 & $0.0006-0.0393$ & 25.6 \\
\hline Lower middle income & 12 & 0.85 & $0.78-0.94$ & $0.65-1.11$ & 75.5 & 0.0154 & $0.0051-0.0540$ & 9.5 \\
\hline Upper middle income & 11 & 0.94 & $0.87-1.02$ & $0.78-1.13$ & 43.0 & 0.0068 & $0.0000-0.0294$ & 22.7 \\
\hline High income & 1 & 2.24 & $0.74-6.78$ & - & - & - & - & - \\
\hline \multicolumn{9}{|l|}{ Zinc salt } \\
\hline Acetate & 5 & 0.96 & $0.89-1.04$ & $0.83-1.11$ & 54.3 & 0.0037 & $0.0000-0.0118$ & 25.1 \\
\hline Gluconate & 7 & 0.91 & $0.87-0.95$ & $0.87-0.95$ & 0.0 & 0.0000 & $0.0000-0.0026$ & - \\
\hline Methionate & 3 & 0.95 & $0.76-1.19$ & $0.63-1.42$ & 74.6 & 0.0267 & $0.0005-0.1466$ & 37.8 \\
\hline Sulphate & 18 & 0.84 & $0.85-0.93$ & $0.60-1.18$ & 75.2 & 0.0276 & $0.0100-0.0742$ & 14.7 \\
\hline Not mentioned & 5 & 0.88 & $0.78-1.00$ & $0.69-1.13$ & 60.0 & 0.0112 & $0.0000-0.1171$ & 11.4 \\
\hline \multicolumn{9}{|l|}{ Duration of supplementation } \\
\hline 2-10 weeks & 3 & 0.92 & $0.82-1.03$ & $0.75-1.13$ & 70.6 & 0.0067 & $0.0049-0.0124$ & 15.4 \\
\hline 10-26 weeks & 15 & 0.85 & $0.78-0.93$ & $0.63-1.14$ & 75.5 & 0.0190 & $0.0056-0.0566$ & 11.9 \\
\hline $27+$ weeks & 20 & 0.94 & $0.89-1.00$ & $0.78-1.13$ & 51.2 & 0.0072 & $0.0000-0.0207$ & 23.3 \\
\hline
\end{tabular}

$\mathrm{N}$, number of study groups; SRR, summary relative risk estimate; $\mathrm{Cl}, 95 \%$ confidence interval based on DerSimonian and Laird model estimates; PI, 95\% prediction interval [details in supplementary note (see Additional File 3)]; $\tau^{2}$, among-study variance; $\mathrm{Cl}$, confidence interval; $\operatorname{Pr}(\mathrm{OE})$, opposite effects proportion

*, For details please see text.

zinc acetate were homogenous but did not show a significant reduction in relative risk of diarrhea. Lastly, we found that the trials supplementing zinc for a duration of 10-26 weeks $[17,19,21,25,26,28,31,33-35,41,47]$ showed a reduced likelihood of diarrhea but trials using zinc supplementation for shorter $[12,18,36]$ or longer $[7,8,10,11,20,23,27,30,37-39,43-46,62]$ duration than this interval did not show a statistically meaningful benefit for the outcome of diarrheal incidence.

One of the main challenges in our meta-analyses was the consideration of co-interventions. Figure 4 shows the network diagram for the various comparisons observed in the included studies. Formal network metaanalysis (mixed treatment comparisons) [66-70] could not be done because the treatment regimens used in various studies (Figure 4) cannot be considered fully discrete $[69,70]$. We thus classified the studies into three groups - those that compared zinc supplementation versus placebo,[7,9-12,20,23,25-28,30,31,33,34,36,37,39, $43,44,47,64]$ those that compared the combination of zinc with some co-intervention that was also given to the reference group (referred to as zinc $+\mathrm{x}$ versus $\mathrm{x}$ in Table 2) $[17-19,35,41]$ and those that combined two more co-interventions with zinc but gave only one cointervention to the reference group (referred to as zinc $+x+y$ versus $y$ in Table 2) $[7,8,19,30,37,38,45,46]$. Interestingly, we observed that (Table 2) the benefit of zinc supplementation could be ascertained from the zinc versus placebo studies as well as the zinc $+\mathrm{x}$ versus $\mathrm{x}$ studies but in the remaining studies this association was not seen.

Next, using meta-regression we found that the dose of zinc $(p=0.321)$, the total amount of zinc received through supplementation $(\mathrm{p}=0.467)$ or duration of zinc supplementation $(\mathrm{p}=0.418)$ did not influence the observed benefit of supplementation and did not 


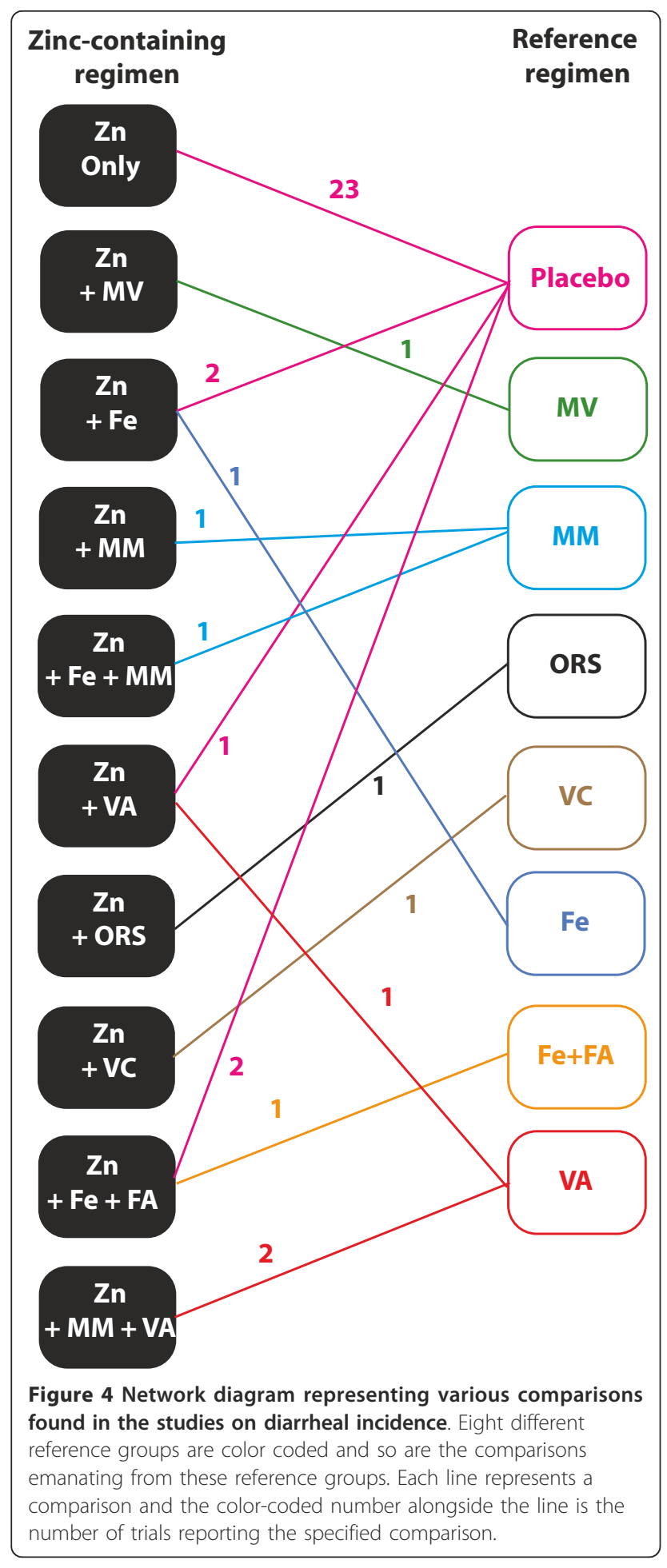

contribute significantly to the between-studies heterogeneity. This result from meta-regression also corroborated the results from subgroup analysis (Table 2) which showed that extremes of the duration of zinc supplementation were not associated with benefit of zinc supplementation. Together, our findings show that age, continent and zinc salt were the three important characteristics that could partly explain the significant heterogeneity of the beneficial association of zinc supplementation in diarrheal incidence.

Lastly, we conducted risk of bias analyses to investigate if existing risks of bias in the included studies could provide clues into the source of among-study heterogeneity. Of the six potential biases investigated for, we observed that a compilation of "other biases" explained $18 \%$ of the among-study heterogeneity ( $\mathrm{p}=$ 0.0309) while the remaining five biases did not individually afflict the among-study heterogeneity in a significant way. Details of these biases for each study are provided in Supplementary Table 2 (see Additional file 3). To consider whether these biases might influence the among-study heterogeneity in a concerted fashion, we meta-regressed the total risk of bias score on the log of reported RRs. We observed that (Figure 5B) there was trend for a more significant association of zinc supplementation with diarrheal incidence in studies that showed a higher risk of bias $(\mathrm{p}=0.062)$. Interestingly, we also observed that there was a statistically significant correlation between mean age in the trial and the risk of bias (Pearson's $\mathrm{r}=0.34, \mathrm{p}=0.038$ ) and therefore when these two variables were together entered into a multivariate meta-regression model, both lost the statistical significance (data not shown). Together these analyses demonstrated that studies with high age group and (sometimes concomitant) higher risk of bias were likely to report a larger benefit attributable to zinc supplementation.

Association of zinc supplementation with other outcomes We next evaluated the influence of zinc supplementation on the remaining four outcomes described in Figure 1 . The summary relative risk estimate for prevalence of diarrhea was contributed by 15 studies [12,23,24,29, $31-36,38,39,43,44,65]$ which enrolled 3501 and 3033 children respectively in zinc and comparison group without zinc. There was a $19 \%$ (summary relative risk estimate $0.81,95 \%$ CI 0.75-0.88; Figure 6) lower prevalence of diarrhea among children who received zinc supplementation. However, there was significant heterogeneity of this effect as indicated by an $\mathrm{I}^{2}$ statistic of $89.5 \%$. For the outcome of incidence of persistent diarrhea 11 studies [21,30,33-36,38-40,45,46] with 12 distinct comparisons which enrolled 31106 and 36899 children in the zinc-supplemented and comparison group, respectively were included in our meta-analysis. Our results showed a non-significant association with on the reduction of risk by $11 \%$ (summary relative risk estimate 0.89 , 95\% CI 0.73-1.09) - a finding that was homogeneous across the included studies $\left(\mathrm{I}^{2} 25 \%\right.$, Figure 6$)$. The summary relative risk estimate for reduction of incidence of 


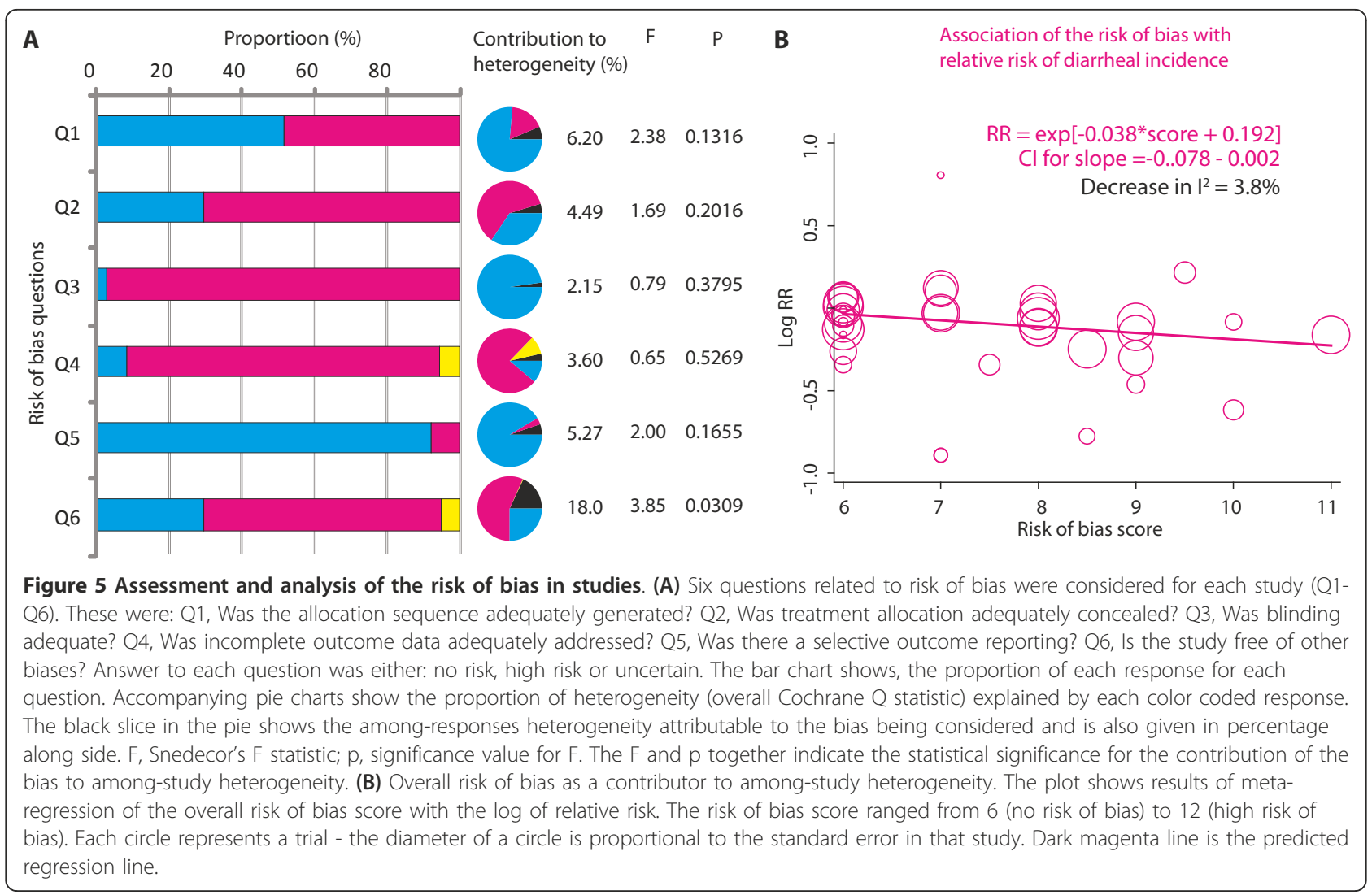

dysentery was estimated from 7 studies $[18,30,34$, $36,40,45,46]$ with 8 distinct comparisons of 33391 and 39446 children respectively in zinc and comparison groups. There was a non significant reduction of $11 \%$ $\left(0.89,95 \%\right.$ CI $0.75-1.06$, Figure 6) with an $\mathrm{I}^{2}$ of $38 \%$ indicating homogeneity across studies. Finally, the effect of zinc on mortality was assessed from 12 studies [10,11, $18,22,23,29,32,42,43,45,46,62]$ showing 14 distinct comparisons enrolling 111790 and 118140 children in zinc and comparison group. Although there was a 10\% reduction in the risk of mortality (summary relative risk estimate $0.90,95 \%$ CI 0.78-1.04, Figure 6) it did not achieve statistical significance and again the findings were homogeneous as indicated by an $\mathrm{I}^{2}$ of $48 \%$ (Figure 4). For these four outcomes, we did not conduct subgroup meta-analyses or meta-regression owing to the small number of studies. For all these outcomes the $95 \%$ prediction intervals included a value of unity. For the outcome of prevalence of diarrhea, exclusion of the Fisher Walker et al trial [12] (due to zinc supplementation during acute diarrhea) did not influence the summary relative risk estimate while exclusion of the Baqui et al [18] trial for the same reason further reduced the likelihood of a beneficial association of zinc supplementation with dysentery. The details of these analyses are provided in supplementary meta-analyses (see Additional file 5).

\section{Discussion}

We reviewed a total of 37 studies that reported the value of zinc supplementation in children for five different diarrhea-related outcomes. We first considered our findings in the light of the three previous meta-analyses of preventive trials [4-6] that had observed a $14-20 \%$ reduction in the incidence of diarrhea in zinc supplemented children. Since significant heterogeneity among trials was observed we compared the point estimates for effect sizes, their $95 \%$ confidence intervals, the total number of studies and children included in this study with those in the previously published meta-analyses (Table 3). Our estimate of the protective benefit of zinc supplementation was consistently lower that that reported in all previous meta-analyses. Further, the $95 \%$ prediction intervals of the summary relative risk estimate for all the five outcomes in this meta-analysis straddled unity. With respect to the outcome of diarrheal incidence however, it should be noted that this outcome essentially deals with all (not just the first) episodes of diarrhea during follow-up and that the three trials that explicitly studied the association of zinc supplementation with multiple episodes of diarrhea did demonstrate a significant benefit for the prevention of $\geq 2$ episodes.

In this study, cumulative meta-analyses helped to sequentially update the summary relative risk estimate 


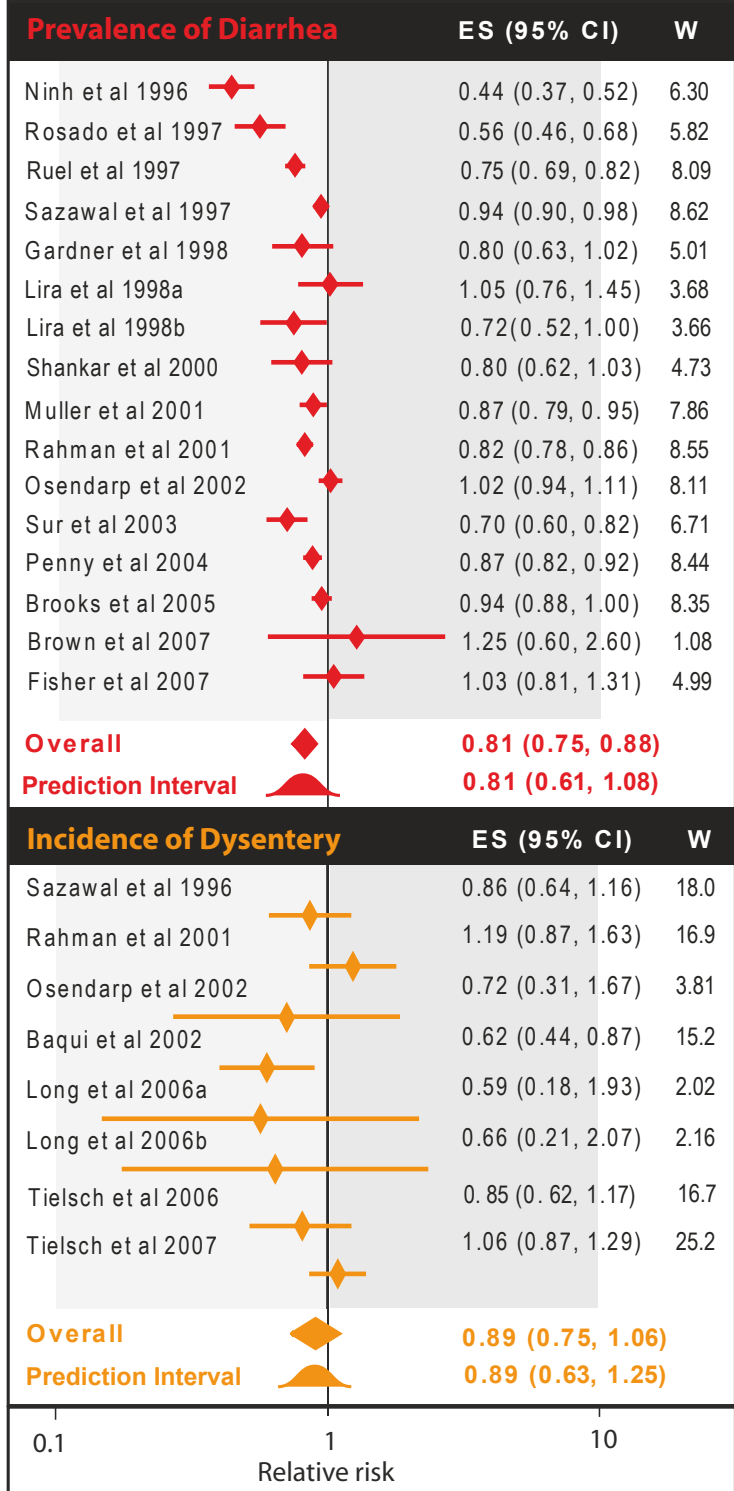

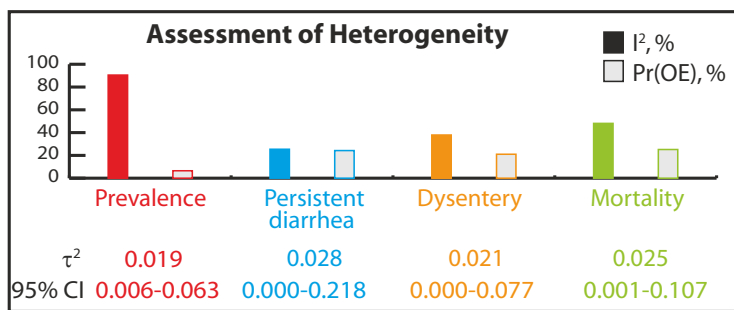

Incidence of Persistent Diarrhea ES (95\% CI) W

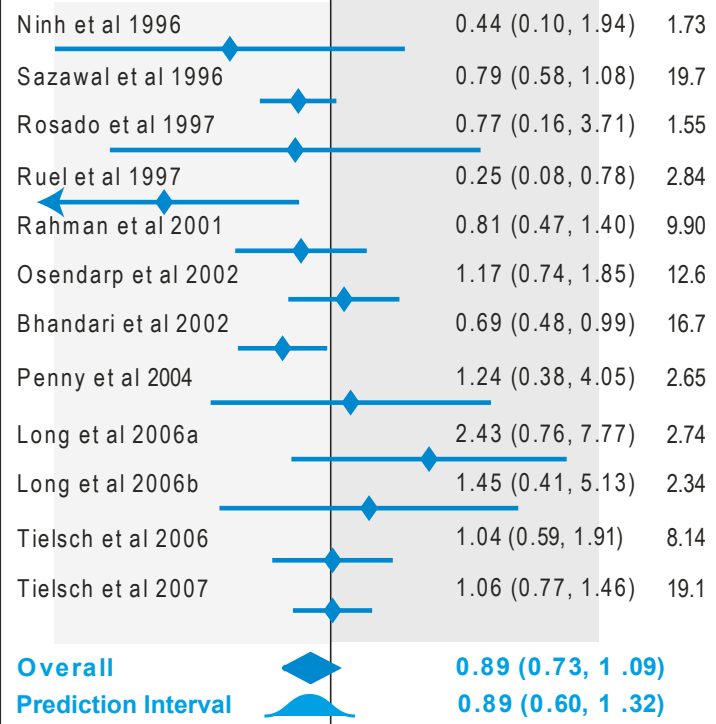

Incidence of Mortality

ES $(95 \% \mathrm{CI}) \quad$ W

\begin{tabular}{|c|c|c|}
\hline Lira et al $1998 \mathrm{a}$ & $0.50(0.13,1.92)$ & 1.05 \\
\hline Lira et al 1998b & $0.53(0.13,2.16)$ & 0.97 \\
\hline Shankar et al 2000 & $3.02(0.32,28.5)$ & 0.39 \\
\hline Muller et al 2001 & $0.32(0.12,0.85)$ & 1.82 \\
\hline Sazawal et al 2001 & $0.49(0.25,0.96)$ & 1.90 \\
\hline Baqui et al 2002 & $0.49(0.25,0.96)$ & 3.66 \\
\hline Brooks et al 2005 & $0.15(0.03,0.75)$ & 0.75 \\
\hline Sazawal et al 2006 & $1.12(0.88,1.43)$ & 13.1 \\
\hline Tielsch et al 2006 & $1.00(0.74,1.35)$ & 10.8 \\
\hline Tielsch et al 2007 & $0.92(0.75,1.13)$ & 14.7 \\
\hline Sazawal et al 2007a & $0.81(0.66,0.99)$ & 14.6 \\
\hline Sazawal et al 2007b & $1.05(0.87,1.27)$ & 15.4 \\
\hline Bhandari et al 2007 & $1.02(0.87,1.20)$ & 16.7 \\
\hline Taneja et al 2009 & $1.07(0.58,1.97)$ & 4.27 \\
\hline Overall & $0.90(0.78,1.04)$ & \\
\hline Prediction Interval & $0.90(0.63,1.28)$ & \\
\hline 0.1 & 10 & \\
\hline
\end{tabular}

Figure 6 Forest plots for the meta-analysis of the influence of preventive zinc supplementation on four diarrhea outcomes- prevalence of diarrhea (red), incidence of persistent diarrhea (blue), incidence of dysentery (orange) and incidence of all-cause mortality (green). Diamonds and error bars indicate the point and 95\% confidence interval observed in each study. ES, effect size; Cl, confidence interval; W, statistical weight for derived from the DerSimonian and Laird random effects model. Summary relative risk estimate size for each outcome is shown as a filled diamond. The 95\% prediction interval is shown as a standard normal curve and the opposite effects proportion $[\operatorname{Pr}(\mathrm{OE})]$ are shown in the box depicting assessment of heterogeneity. Suffixes $a$ and $b$ to some studies indicate two comparisons within a single study against the same placebo as detailed in Supplementary Table (see Additional File 4). Light grey background indicates beneficial effect of zinc and dark grey background indicates a harmful effect of zinc. Degree of heterogeneity across studies in the meta-analysis for each outcome is shown as colorcoded pie-charts on the lower-left. The filled slice in the pie-charts indicates the $\mathrm{I}^{2}$ statistic. Also shown are the values of $\tau^{2}$ along with the $95 \%$ confidence interval, the among-study variance for each outcome. 
Table 3 Comparison of the results our study with those published previously

\begin{tabular}{|c|c|c|c|c|c|c|c|}
\hline Outcome & Meta-analysis & RCTs & $\mathrm{N}$ & Statistic & Point Estimate & $95 \% \mathrm{Cl}$ & $I^{2}(\%)$ \\
\hline \multirow[t]{4}{*}{ Incidence of diarrhea } & M1 & 7 & 1502 & OR & 0.82 & $0.72-0.93$ & - \\
\hline & M2 & 15 & 6272 & RR & 0.86 & $0.79-0.93$ & 77.3 \\
\hline & M3 & 24 & 16665 & $\mathrm{RR}$ & 0.80 & $0.71-0.90$ & - \\
\hline & This study & 31 & 144962 & RR & 0.91 & $0.86-0.95$ & 65.5 \\
\hline \multirow[t]{2}{*}{ Prevalence of diarrhea } & M1 & 7 & 1502 & OR & 0.75 & $0.63-0.88$ & - \\
\hline & This study & 15 & 6534 & RR & 0.81 & $0.75-0.88$ & 89.5 \\
\hline \multirow[t]{3}{*}{ Incidence of persistent diarrhea } & M1 & 6 & 1770 & OR & 0.67 & $0.42-1.06$ & - \\
\hline & M2 & 3 & 2585 & RR & 0.75 & $0.57-0.98$ & 56.3 \\
\hline & This study & 11 & 68005 & $\mathrm{RR}$ & 0.89 & $0.73-1.09$ & 25.4 \\
\hline \multirow[t]{3}{*}{ Incidence of dysentery } & M1 & 3 & 884 & OR & 0.87 & $0.64-1.19$ & - \\
\hline & $\mathrm{M} 2$ & 4 & 4250 & RR & 0.85 & $0.75-0.95$ & 30.3 \\
\hline & This study & 7 & 72837 & $\mathrm{RR}$ & 0.89 & $0.75-1.06$ & 37.9 \\
\hline \multirow[t]{3}{*}{ Mortality } & M4 & 4 & 86152 & $\mathrm{RR}$ & 0.91 & $0.82-1.02$ & - \\
\hline & M3 & 10 & 201616 & RR & 0.94 & $0.86-1.02$ & - \\
\hline & This study & 12 & 229930 & RR & 0.90 & $0.78-1.04$ & 48.1 \\
\hline
\end{tabular}

- , not reported

M1, Bhutta et al 1999[5]; M2, Aggarwal et al 2007[4]; M3, Brown et al 2009[6]; M4, Tielsch et al 2007[45]

$\mathrm{OR}$, odds ratio; $\mathrm{RR}$, relative risk; $\mathrm{RCT}$, randomized controlled trial; $\mathrm{Cl}$, confidence interval

size by incorporating results from each newly available study and also assess its impact on the heterogeneity. We observed a steady decline in the protective afforded by zinc with a corresponding decline in the heterogeneity which however remained significant $\left(\mathrm{I}^{2}=65.5 \%\right)$ till the inclusion of the last study. Our investigation into the potential sources of the observed heterogeneity of results raises several interesting and important possibilities. First, since a distinct slope for the effect size is visualized (Figure 2C), it indicates instability of the pooled effect size[71,72]. This instability indicates that more and more negative studies (that is, studies reporting no clear benefit of zinc supplementation) have accumulated over the recent past (a finding affirmed by our subgroup analyses) and thus the clear benefit of zinc observed during early years appears to have shrunken or elapsed from more recent studies.

Second, it may be possible that there is a substantial variability in the microbiological spectrum of the causes of acute diarrhea across the studies. We have recently [73] reported that the therapeutic benefit of zinc is not equal against all organisms such that the Klebsiella spp were most responsive to zinc supplementation, Esherichia coli were neutral while rotavirus diarrhea was associated with worse outcomes in zinc supplemented children. It is conceivable that a similar phenomenon may be operative in the scenario of diarrhea prevention as well. This notion is also indirectly supported by our observations that a significant benefit of zinc is not universally observed across continents of study origin or countries classified on the basis of economy both of which may somewhat reflect the heterogeneity in the microbiological spectrum of causative organisms.

Third, in our meta-regression analyses, age was significantly associated with the magnitude of the beneficial association of zinc supplementation and explained $6 \%$ of the heterogeneity. The restricted meta-analyses showed a steep decline in the protection below 12 months of age (Figure 3A, B). The previous meta-analyses of 24 studies with 33 distinct comparisons also validated that the benefit of zinc supplements on diarrhea incidence was limited to studies of children with mean initial age greater than 12 months [6]. Considered in the light of the causal gamut of childhood diarrheas, it is likely that the more common pathogens at age below 12 months (for example, rotavirus infections) may be refractory to the benefit of zinc supplementation at least as observed in the context of diarrhea treatment. This finding indicates that zinc supplementation may benefit substantially by triaging on the basis of age.

Combined with these findings we also found that the studies that recruited higher age groups seemed also to be a higher risk of biases. Consequently, there is a putative circular relationship among age, bias and observed effect. Alternative interpretations are possible in such a scenario and the true interpretation is currently unknown. For example, on the one hand it can be argued (as stated thus far) that zinc may be beneficial at higher age in reducing the prevalence and incidence of diarrhea. On the other hand, it can also be argued that the observed benefit of zinc at higher ages may be influenced by implicit study biases and that more carefully 
done and reported studies in children with higher age are likely to shed more light on the magnitude of a true zinc benefit in diarrhea prevention.

Fourth, the sub-group analyses also showed that zinc salts may have a differential bearing on diarrheal incidence. Studies that used zinc gluconate showed homogeneity and significant reduction in diarrheal incidence $\left(\mathrm{I}^{2} 0 \%\right.$, summary relative risk estimate $0.90,95 \%$ CI 0.86 - 0.94). Those using zinc sulfate were heterogeneous but showed a statistically significant reduction in diarrheal incidence $\left(\mathrm{I}^{2} 84.3 \%\right.$, summary relative risk estimate 0.75 , $95 \%$ CI 0.63 - 0.89). There were fewer studies that used zinc acetate and showed no benefit of zinc but were homogenous. Elsewhere, we reported that a sub-group analyses of therapeutic effect of zinc in reduction of diarrheal duration also showed that studies using zinc gluconate had a significant homogeneous reduction in diarrheal duration although increased the risk of vomiting[74]. These findings beckon a reconsideration of the policy formulations regarding the salt to be used for large scale zinc supplementation program aimed at diarrhea prevention. Together, these findings from cumulative and sub-group analyses provide clues into the heterogeneity of results from various studies of zinc supplementation for diarrhea prevention.

It is noteworthy that Asia has the largest population of stunted children[75-77]. It is expected that those countries at high risk of zinc deficiency, i.e. prevalence stunting exceeding $20 \%$ and estimated prevalence of inadequate zinc intake of more than $25 \%$, would most likely benefit from prophylactic and therapeutic zinc supplementation[78]. In this context it is interesting that our findings from the sub-group analyses that studies only from Asia demonstrated a favorable association of zinc supplementation albeit with significant heterogeneity. Despite the food insecurity and poverty in developing countries of both Asia and Africa, studies from Africa did not show a significant beneficial association of zinc in reducing the risk of diarrhea and were homogenous. Anthropometric indices, baseline plasma zinc levels or use of co-interventions may have differed between studies in these continents.

Our estimate of the influence of zinc on the prevalence of diarrhea was slightly lower than that reported by Bhutta et al[5] over a decade ago (Table 1). However, that outcome had the highest heterogeneity across studies and therefore, although appealing, the summary relative risk estimate size should be (metaphorically) taken with a pinch of salt. More homogeneous studies are needed before a conclusive impact of zinc can be deduced on prevalence of diarrhea. In contrast to the benefit of zinc for incidence and prevalence of diarrhea, we could not demonstrate a clear benefit of this intervention in reducing the incidence of persistent diarrhea, dysentery and mortality. Two previous meta-analyses that reported the effect of zinc on persistent diarrhea reached opposite conclusions (Table 3) - one [4] showed a significant effect while the other did not [5]. In contrast, therapeutic zinc supplementation during acute diarrhea has been reported to have a clear benefit in reducing the incidence of persistent diarrhea by $\sim 25 \%$ and in reducing the proportion of children with persistent diarrhea $>3$ days by $\sim 30 \%[74]$. This advantage of zinc supplementation however does not appear to be extending to prevention of persistent diarrhea. Similar inconsistency was also observed for the effect of zinc on the incidence of dysentery (Table 1). These results imply that prevention of persistent diarrhea and dysentery may not serve as realistic goals for preventive zinc supplementation.

Finally, Tielsch et al [45] conducted a meta-analysis of the effects of zinc supplementation on young child mortality using two reports from South Asia and two from Sub-Saharan Africa. The pooled estimated relative risk of mortality across all ages for zinc supplementation was 0.91 (95\% CI 0.82-1.02). A post hoc analysis showed that zinc had a protective effect against mortality only in children over 12 months [OR 0.82, 95\% confidence interval (CI) $0.70-0.96$ ] ; and in infants there was no effect (OR 1.04 95\% CI 0.90 - 1.21). The mortality diminishing effects of zinc supplementation were also equivocal in the subsequent review which included 10 studies (Table 1)[6]. Our systematic review shows that adequately powered trials failed to demonstrate a significant mortality reducing association of zinc supplementation in children less than five years. Based on these data, we surmise that currently it is too premature to definitively conclude about the role of preventive zinc supplementation on mortality. However, it should also be borne that our meta-analysis as well as the two previous meta-analyses $[6,45]$ have attempted to study the effect of zinc supplementation on all-cause mortality. It is possible that zinc supplementation may have more pronounced effect on diarrhea-related or pneumoniarelated mortality $[4,64]$ which may have been masked when considering all-cause mortality.

Our meta-analyses had several strengths. First, as shown in Table 3 our meta-analyses studied all the five outcomes which, to our knowledge, no other study has done in the past. Second, our meta-analyses were based on several additional studies that the previous reviews did not include. Third, cumulative meta-analyses included in our study provided additional insights into the chronological change in the pattern of zinc benefit. Finally we attempted to probe the observed heterogeneity and conducted meta-regression and sub-analyses to explain it. Our study also has several limitations. First, only a few studies reported information on most of the 
predictor variables simultaneously so multivariate metaregression analyses could not be conducted to understand the importance of the factors identified in a multivariate context. Second, only covariates reported in the trials can be examined but conceivably other known and unknown predictors of zinc benefit may also partly explain the observed heterogeneity. Third, meta-regression and subgroup analyses, in themselves, cannot be considered as diagnostic tools but just provide clues into the possible sources of heterogeneity. Fourth, due to lack of reported data we could not fully tease out the potential influence of socio-economic and nutritional determinants of the differential benefit of zinc supplementation. Fifth, we consistently observed a high degree of heterogeneity across studies (sometimes even within subgroups). Such high degree of heterogeneity can be seen as a reason enough to question the validity of the summary effect measures which might reflect an oversimplification of the truth. Together, our findings urge that more focused investigation of the potential sources of heterogeneity is needed to refine and improve the benefits from zinc supplementation for prevention of diarrhea.

\section{Conclusions}

We observed that zinc supplementation reduces incidence of diarrhea by $9 \%$ with more pronounced association observed beyond 12 months of age. We attempted to translate this benefit into a perceptible public health measure. A limitation of relative risk as a measure of association is that decision making also needs information on the extent of baseline risk. From a practical perspective, measures such as number needed to treat (NNT), which rely on the absolute rather than relative risk reduction, are more informative [79-82]. Using the results of our meta-analyses, we therefore estimated the number needed to prevent (NNP) diarrheal episodes. An NNP of unity indicates that all eligible children be provided the preventive intervention[83]. Using the mathematical relationship among relative risk, baseline risk, absolute risk reduction and NNP, we determined that an NNP of unity can be achieved if the prevalence of children with at least one diarrheal episode in year is $13.74 \%$ (95\% CI $9.40 \%-26.60 \%$ ). Thus zinc supplementation of eligible children would be appropriate for this range of prevalence of diarrheal episodes. It should also be noted that we observed a significant benefit of zinc supplementation against multiple episodes of diarrhea. However our cumulative meta-analyses showed that the strength of benefit of zinc supplementation appears to be shrinking as more studies are getting published. Also, almost all the $95 \%$ prediction intervals reported in this meta-analyses seemed to straddle unity suggesting that a reproducible clear benefit of zinc supplementation cannot be confidently inferred from the existing evidence. Therefore the strategy of prophylactic zinc supplementation for diarrheal prevention needs to be finetuned. We also observed that zinc supplementation had no demonstrable benefit against incidence of persistent diarrhea, dysentery and mortality in children however it should also be noted that the summary relative risk estimate was consistently less than unity for all outcomes. There is a continued need to understand sources of heterogeneity between studies so that zinc supplementation targets the population that is most likely to benefit.

\section{Additional material}

Additional file 1: PRISMA 2009 checklist. Checklist including relevant page numbers for identifying various components of the review

Additional file 2: PRISMA 2009 Flow Diagram. Flowchart detailing the trial recruitment protocol used in this review

Additional file 3: Supplementary Note. Supplementary Note describing the merits of the $\tau^{2}$ statistic over the $I^{2}$ statistic for measurement of heterogeneity across studies

Additional file 4: Supplementary Tables. Supplementary Table describing additional trial characteristics

Additional file 5: Additional Meta-analyses. Additional meta-analyses by excluding two trials that used zinc supplementation during episodes of acute diarrhea

\section{Abbreviations}

Cl: Confidence interval; ES: Effect size; NNP: Number needed to prevent; NNT: Number needed to treat; PI: Prediction interval; PRISMA: Preferred Reporting Items for Systematic Reviews and Meta-Analyses; RCT: Randomized controlled trial; SRR: Summary relative risk; UNICEF: United Nations Children's Fund; WHO: World Health Organization;

\section{Author details}

${ }^{1}$ Lata Medical Research Foundation, Nagpur, India. ${ }^{2}$ Indira Gandhi Government Medical College, Nagpur, India. ${ }^{3}$ The University of Texas Health Science Center at San Antonio, Texas, USA.

\section{Authors' contributions}

ABP conceptualized the study, carried our data abstraction and wrote the manuscript; MM conceptualized the study, carried our data abstraction, conducted some analyses and wrote the manuscript; NB conducted statistical analyses and helped during the initial writing of the manuscript; HK conceptualized the study, carried out data abstractions, conducted analyses and wrote the manuscript and all authors have read and approve the manuscript.

\section{Competing interests}

The authors declare that they have no competing interests.

Received: 25 January 2011 Accepted: 12 May 2011

Published: 12 May 2011

\section{References}

1. Larson CP, Roy SK, Khan Al, Rahman AS, Qadri F: Zinc treatment to underfive children: applications to improve child survival and reduce burden of disease. J Health Popul Nutr 2008, 26:356-365.

2. Salvatore S, Hauser B, Devreker T, Vieira MC, Luini C, Arrigo S, Nespoli L, Vandenplas $Y$ : Probiotics and zinc in acute infectious gastroenteritis in children: are they effective? Nutrition 2007, 23:498-506. 
3. WHO/UNICEF: WHO/UNICEF joint statement: clinical management of acute diarrhoea Geneva, Switzerland: WHO/UNICEF; 2004

4. Aggarwal R, Sentz J, Miller MA: Role of zinc administration in prevention of childhood diarrhea and respiratory illnesses: a meta-analysis. Pediatrics 2007, 119:1120-1130.

5. Bhutta ZA, Black RE, Brown KH, Gardner JM, Gore S, Hidayat A, Khatun F, Martorell R, Ninh NX, Penny ME, et al: Prevention of diarrhea and pneumonia by zinc supplementation in children in developing countries: pooled analysis of randomized controlled trials. Zinc Investigators' Collaborative Group. J Pediatr 1999, 135:689-697.

6. Brown KH, Peerson JM, Baker SK, Hess SY: Preventive zinc supplementation among infants, preschoolers, and older prepubertal children. Food Nutr Bull 2009, 30:S12-40.

7. Chhagan MK, Van den Broeck J, Luabeya KK, Mpontshane N, Tucker KL, Bennish ML: Effect of micronutrient supplementation on diarrhoeal disease among stunted children in rural South Africa. Eur J Clin Nutr 2009.

8. Luabeya KK, Mpontshane N, Mackay M, Ward H, Elson I, Chhagan M, Tomkins A, Van den Broeck J, Bennish ML: Zinc or multiple micronutrient supplementation to reduce diarrhea and respiratory disease in South African children: a randomized controlled trial. PLOS One 2007, 2:e541.

9. Sazawal S, Black RE, Ramsan M, Chwaya HM, Dutta A, Dhingra U, Stoltzfus RJ, Othman MK, Kabole FM: Effect of zinc supplementation on mortality in children aged 1-48 months: a community-based randomised placebo-controlled trial. Lancet 2007, 369:927-934.

10. Sazawal S, Black RE, Ramsan M, Chwaya HM, Stoltzfus RJ, Dutta A, Dhingra U, Kabole I, Deb S, Othman MK, Kabole FM: Effects of routine prophylactic supplementation with iron and folic acid on admission to hospital and mortality in preschool children in a high malaria transmission setting: community-based, randomised, placebo-controlled trial. Lancet 2006, 367:133-143.

11. Taneja S, Bhandari N, Rongsen-Chandola T, Mahalanabis D, Fontaine $O$, Bhan MK: Effect of zinc supplementation on morbidity and growth in hospital-born, low-birth-weight infants. Am J Clin Nutr 2009, 90:385-391.

12. Walker CL, Bhutta ZA, Bhandari N, Teka T, Shahid F, Taneja S, Black RE: Zinc during and in convalescence from diarrhea has no demonstrable effect on subsequent morbidity and anthropometric status among infants $<6$ mo of age. Am J Clin Nutr 2007, 85:887-894.

13. Bobat R, Coovadia H, Stephen C, Naidoo KL, Mckerrow N, Black RE, Moss WJ: Safety and efficacy of zinc supplementation for children with HIV-1 infection in South Africa: a randomised double-blind placebocontrolled trial. Lancet 2005, 366:1862-1867.

14. Wuehler SE, Sempertegui F, Brown KH: Dose-response trial of prophylactic zinc supplements, with or without copper, in young Ecuadorian children at risk of zinc deficiency. Am J Clin Nutr 2008, 87:723-733.

15. Castillo-Duran C, Perales CG, Hertrampf ED, Marin VB, Rivera FA, Icaza G: Effect of zinc supplementation on development and growth of Chilean infants. J Pediatr 2001, 138:229-235.

16. Yang $Y X$, Han JH, Shao XP, He M, Bian LH, Wang Z, Wang GD, Men JH: Effect of micronutrient supplementation on the growth of preschool children in China. Biomed Environ Sci 2002, 15:196-202.

17. Alarcon K, Kolsteren PW, Prada AM, Chian AM, Velarde RE, Pecho IL, Hoeree TF: Effects of separate delivery of zinc or zinc and vitamin A on hemoglobin response, growth, and diarrhea in young Peruvian children receiving iron therapy for anemia. Am J Clin Nutr 2004, 80:1276-1282.

18. Baqui AH, Black RE, El Arifeen S, Yunus M, Chakraborty J, Ahmed S, Vaughan JP: Effect of zinc supplementation started during diarrhoea on morbidity and mortality in Bangladeshi children: community randomised trial. Bmj 2002, 325:1059.

19. Baqui AH, Zaman K, Persson LA, El Arifeen S, Yunus M, Begum N, Black RE: Simultaneous weekly supplementation of iron and zinc is associated with lower morbidity due to diarrhea and acute lower respiratory infection in Bangladeshi infants. J Nutr 2003, 133:4150-4157.

20. Bates CJ, Evans PH, Dardenne M, Prentice A, Lunn PG, Northrop-Clewes CA, Hoare S, Cole TJ, Horan SJ, Longman SC, et al: A trial of zinc supplementation in young rural Gambian children. Br J Nutr 1993, 69:243-255

21. Bhandari N, Bahl R, Taneja S, Strand T, Molbak K, Ulvik RJ, Sommerfelt H, Bhan MK: Substantial reduction in severe diarrheal morbidity by daily zinc supplementation in young north Indian children. Pediatrics 2002, 109:e86.
22. Bhandari N, Taneja S, Mazumder S, Bahl R, Fontaine O, Bhan MK: Adding zinc to supplemental iron and folic acid does not affect mortality and severe morbidity in young children. J Nutr 2007, 137:112-117.

23. Brooks WA, Santosham M, Naheed A, Goswami D, Wahed MA, DienerWest M, Faruque AS, Black RE: Effect of weekly zinc supplements on incidence of pneumonia and diarrhoea in children younger than 2 years in an urban, low-income population in Bangladesh: randomised controlled trial. Lancet 2005, 366:999-1004.

24. Brown KH, Lopez de Romana D, Arsenault JE, Peerson JM, Penny ME: Comparison of the effects of zinc delivered in a fortified food or a liquid supplement on the growth, morbidity, and plasma zinc concentrations of young Peruvian children. Am J Clin Nutr 2007, 85:538-547.

25. Gupta DN, Mondal SK, Ghosh S, Rajendran K, Sur D, Manna B: Impact of zinc supplementation on diarrhoeal morbidity in rural children of West Bengal, India. Acta Paediatr 2003, 92:531-536.

26. Gupta DN, Rajendran K, Mondal SK, Ghosh S, Bhattacharya SK: Operational feasibility of implementing community-based zinc supplementation: impact on childhood diarrheal morbidity. Pediatr Infect Dis J 2007, 26:306-310.

27. Heinig MJ, Brown KH, Lonnerdal B, Dewey KG: Zinc supplementation does not affect growth, morbidity, or motor development of US term breastfed infants at 4-10 mo of age. Am J Clin Nutr 2006, 84:594-601.

28. Lind T, Lonnerdal B, Stenlund H, Gamayanti IL, Ismail D, Seswandhana R, Persson LA: A community-based randomized controlled trial of iron and zinc supplementation in Indonesian infants: effects on growth and development. Am J Clin Nutr 2004, 80:729-736.

29. Lira Pl, Ashworth A, Morris SS: Effect of zinc supplementation on the morbidity, immune function, and growth of low-birth-weight, full-term infants in northeast Brazil. Am J Clin Nutr 1998, 68:418S-424S.

30. Long KZ, Montoya Y, Hertzmark E, Santos JI, Rosado JL: A double-blind, randomized, clinical trial of the effect of vitamin $A$ and zinc supplementation on diarrheal disease and respiratory tract infections in children in Mexico City, Mexico. Am J Clin Nutr 2006, 83:693-700.

31. Meeks Gardner JM, Witter MM, Ramdath DD: Zinc supplementation: effects on the growth and morbidity of undernourished Jamaican children. Eur J Clin Nutr 1998, 52:34-39.

32. Muller $\mathrm{O}$, Becher $\mathrm{H}$, van Zweeden $\mathrm{AB}$, Ye $\mathrm{Y}$, Diallo DA, Konate AT, Gbangou A, Kouyate B, Garenne M: Effect of zinc supplementation on malaria and other causes of morbidity in west African children: randomised double blind placebo controlled trial. Bmj 2001, 322:1567.

33. Ninh NX, Thissen JP, Collette L, Gerard G, Khoi HH, Ketelslegers JM: Zinc supplementation increases growth and circulating insulin-like growth factor I (IGF-I) in growth-retarded Vietnamese children. Am J Clin Nutr 1996, 63:514-519.

34. Osendarp SJ, Santosham M, Black RE, Wahed MA, van Raaij JM, Fuchs GJ: Effect of zinc supplementation between 1 and 6 mo of life on growth and morbidity of Bangladeshi infants in urban slums. Am J Clin Nutr 2002, 76:1401-1408.

35. Penny ME, Marin RM, Duran A, Peerson JM, Lanata CF, Lonnerdal B, Black RE, Brown KH: Randomized controlled trial of the effect of daily supplementation with zinc or multiple micronutrients on the morbidity, growth, and micronutrient status of young Peruvian children. Am J Clin Nutr 2004, 79:457-465.

36. Rahman MM, Vermund SH, Wahed MA, Fuchs GJ, Baqui AH, Alvarez JO: Simultaneous zinc and vitamin A supplementation in Bangladeshi children: randomised double blind controlled trial. Bmj 2001, 323:314-318.

37. Richard SA, Zavaleta N, Caulfield LE, Black RE, Witzig RS, Shankar AH: Zinc and iron supplementation and malaria, diarrhea, and respiratory infections in children in the Peruvian Amazon. Am J Trop Med Hyg 2006, 75:126-132.

38. Rosado JL, Lopez P, Munoz E, Martinez H, Allen LH: Zinc supplementation reduced morbidity, but neither zinc nor iron supplementation affected growth or body composition of Mexican preschoolers. Am J Clin Nutr 1997, 65:13-19

39. Ruel MT, Rivera JA, Santizo MC, Lonnerdal B, Brown KH: Impact of zinc supplementation on morbidity from diarrhea and respiratory infections among rural Guatemalan children. Pediatrics 1997, 99:808-813.

40. Sazawal S, Black RE, Bhan MK, Jalla S, Bhandari N, Sinha A, Majumdar S: Zinc supplementation reduces the incidence of persistent diarrhea and dysentery among low socioeconomic children in India. J Nutr 1996, 126:443-450. 
41. Sazawal S, Black RE, Bhan MK, Jalla S, Sinha A, Bhandari N: Efficacy of zinc supplementation in reducing the incidence and prevalence of acute diarrhea-a community-based, double-blind, controlled trial. Am J Clin Nutr 1997, 66:413-418.

42. Sazawal $S$, Black RE, Menon VP, Dinghra P, Caulfield LE, Dhingra U, Bagati A: Zinc supplementation in infants born small for gestational age reduces mortality: a prospective, randomized, controlled trial. Pediatrics 2001, 108:1280-1286.

43. Shankar AH, Genton B, Baisor M, Paino J, Tamja S, Adiguma T, Wu L, Rare L, Bannon D, Tielsch JM, et al: The influence of zinc supplementation on morbidity due to Plasmodium falciparum: a randomized trial in preschool children in Papua New Guinea. Am J Trop Med Hyg 2000, 62:663-669.

44. Sur D, Gupta DN, Mondal SK, Ghosh S, Manna B, Rajendran K, Bhattacharya SK: Impact of zinc supplementation on diarrheal morbidity and growth pattern of low birth weight infants in kolkata, India: a randomized, double-blind, placebo-controlled, community-based study. Pediatrics 2003, 112:1327-1332.

45. Tielsch JM, Khatry SK, Stoltzfus RJ, Katz J, LeClerq SC, Adhikari R, Mullany LC, Black R, Shresta S: Effect of daily zinc supplementation on child mortality in southern Nepal: a community-based, cluster randomised, placebocontrolled trial. Lancet 2007, 370:1230-1239.

46. Tielsch JM, Khatry SK, Stoltzfus RJ, Katz J, LeClerq SC, Adhikari R, Mullany LC, Shresta S, Black RE: Effect of routine prophylactic supplementation with iron and folic acid on preschool child mortality in southern Nepal: community-based, cluster-randomised, placebo-controlled trial. Lancet 2006, 367:144-152.

47. Umeta M, West CE, Haidar J, Deurenberg P, Hautvast JG: Zinc supplementation and stunted infants in Ethiopia: a randomised controlled trial. Lancet 2000, 355:2021-2026.

48. DerSimonian R, Laird N: Meta-analysis in clinical trials. Control Clin Trials 1986, 7:177-188.

49. Viechtbauer W: Confidence intervals for the amount of heterogeneity in meta-analysis. Stat Med 2007, 26:37-52.

50. Higgins JP, Thompson SG: Quantifying heterogeneity in a meta-analysis. Stat Med 2002, 21:1539-1558.

51. Poole C: Commentary: Learning from within-study and among-study comparisons-trials of zinc supplementation and childhood acute lower respiratory illness episodes in the developing world. Int J Epidemiol 39:809-811.

52. Higgins JP, Thompson SG, Spiegelhalter DJ: A re-evaluation of randomeffects meta-analysis. J R Stat Soc Ser A Stat Soc 2009, 172:137-159.

53. Poole C: Review of submitted manuscript. 2010.

54. Sterne JA, Egger M: Funnel plots for detecting bias in meta-analysis: guidelines on choice of axis. J Clin Epidemiol 2001, 54:1046-1055.

55. Egger M, Smith GD, Sterne JA: Uses and abuses of meta-analysis. Clin Med 2001, 1:478-484.

56. Duval S, Tweedie R: Trim and fill: A simple funnel-plot-based method of testing and adjusting for publication bias in meta-analysis. Biometrics 2000, 56:455-463.

57. Higgins JP, Altman DG: Chapter 8: Assessing risk of bias in included studies. Cochrane Handbook for Systematic Reviews of Interventions The Cochrane Collaboration; 2008, Volume Version 5.0.1.

58. Thompson SG, Higgins JP: How should meta-regression analyses be undertaken and interpreted? Stat Med 2002, 21:1559-1573.

59. Darlington GA, Donner A: Meta-analysis of community-based cluster randomization trials with binary outcomes. Clin Trials 2007, 4:491-498.

60. Donner A, Klar N: Issues in the meta-analysis of cluster randomized trials. Stat Med 2002, 21:2971-2980

61. Deeks JJ, Altman DG, Bradburn MJ: Statistical methods for examining heterogeneity and combining results from several studies in metaanalysis. In Systematic Reviews in Health Care: Meta-Analysis in Context. 2 edition. Edited by: Egger M, Davey Smith G, Altman DG. London: BMJ; 2001.

62. Sazawal S, Dhingra U, Deb S, Bhan MK, Menon VP, Black RE: Effect of zinc added to multi-vitamin supplementation containing low-dose vitamin $\mathrm{A}$ on plasma retinol level in children-a double-blind randomized controlled trial. J Health Popul Nutr 2007, 25:62-66.

63. Roth DE, Richard SA, Black RE: Zinc supplementation for the prevention of acute lower respiratory infection in children in developing countries: meta-analysis and meta-regression of randomized trials. Int J Epidemiol 39:795-808.

64. Bhandari N, Bahl R, Taneja S, Strand T, Molbak K, Ulvik RJ, Sommerfelt H, Bhan MK: Effect of routine zinc supplementation on pneumonia in children aged 6 months to 3 years: randomised controlled trial in an urban slum. Bmj 2002, 324:1358.

65. Sazawal S, Jalla S, Mazumder S, Sinha A, Black RE, Bhan MK: Effect of zinc supplementation on cell-mediated immunity and lymphocyte subsets in preschool children. Indian Pediatr 1997, 34:589-597.

66. Caldwell DM, Welton NJ, Ades AE: Mixed treatment comparison analysis provides internally coherent treatment effect estimates based on overviews of reviews and can reveal inconsistency. J Clin Epidemiol 63:875-882.

67. Dias S, Welton NJ, Caldwell DM, Ades AE: Checking consistency in mixed treatment comparison meta-analysis. Stat Med 29:932-944.

68. Lu G, Ades A: Modeling between-trial variance structure in mixed treatment comparisons. Biostatistics 2009, 10:792-805.

69. Nixon RM, Bansback N, Brennan A: Using mixed treatment comparisons and meta-regression to perform indirect comparisons to estimate the efficacy of biologic treatments in rheumatoid arthritis. Stat Med 2007, 26:1237-1254.

70. Salanti G, Marinho V, Higgins JP: A case study of multiple-treatments meta-analysis demonstrates that covariates should be considered. J Clin Epidemiol 2009, 62:857-864

71. Muellerleile P, Mullen B: Sufficiency and stability of evidence for public health interventions using cumulative meta-analysis. Am J Public Health 2006, 96:515-522.

72. Mullen B, Muerllereile P, Bryant B: Cumulative meta-analysis: a consideration of indicators of sufficiency and stability. Pers Soc Psychol Bull 2001, 27:1450e1462.

73. Patel AB, Dibley MJ, Mamtani M, Badhoniya N, Kulkarni H: Influence of zinc supplementation in acute diarrhea differs by the isolated organism. Int J Pediatr 2010, 2010:671587.

74. Patel A, Mamtani M, Dibley MJ, Badhoniya N, Kulkarni H: Therapeutic value of zinc supplementation in acute and persistent diarrhea: a systematic review. PLoS One 5:e10386.

75. Faruque AS, Ahmed AM, Ahmed T, Islam MM, Hossain MI, Roy SK, Alam N, Kabir I, Sack DA: Nutrition: basis for healthy children and mothers in Bangladesh. J Health Popul Nutr 2008, 26:325-339.

76. Khor GL: Update on the prevalence of malnutrition among children in Asia. Nepal Med Coll J 2003, 5:113-122.

77. Khor GL: Micronutrient status and intervention programs in Malaysia. Food Nutr Bull 2005, 26:S281-285.

78. Black RE, Allen LH, Bhutta ZA, Caulfield LE, de Onis M, Ezzati M, Mathers C, Rivera J: Maternal and child undernutrition: global and regional exposures and health consequences. Lancet 2008, 371:243-260.

79. Akobeng AK: Communicating the benefits and harms of treatments. Arch Dis Child 2008, 93:710-713.

80. Carneiro AV: Relative risk, absolute risk and number needed to treat: basic concepts. Rev Port Cardiol 2009, 28:83-87.

81. Cheng R, Cook K, Dowman S, Lawn R, Leary J, Quinn T, Schroder K, Smith N, Tordoff J: Health professionals: how do they assess new medicines? Pharm World Sci 2005, 27:236-242.

82. Nuovo J, Melnikow J, Chang D: Reporting number needed to treat and absolute risk reduction in randomized controlled trials. Jama 2002, 287:2813-2814.

83. Oldridge N, Perkins A, Marchionni N, Fumagalli S, Fattirolli F, Guyatt G: Number needed to treat in cardiac rehabilitation. $J$ Cardiopulm Rehabil 2002, 22:22-30.

\section{Pre-publication history}

The pre-publication history for this paper can be accessed here: http://www.biomedcentral.com/1471-2334/11/122/prepub

doi:10.1186/1471-2334-11-122

Cite this article as: Patel et al:: What zinc supplementation does and does not achieve in diarrhea prevention: a systematic review and metaanalysis. BMC Infectious Diseases 2011 11:122. 